\title{
Taxonomic studies of lycophytes and ferns from the Pan-Himalaya (I): Hymenophyllum (Hymenophyllaceae)
}

\author{
T. Y. Nwe ${ }^{1,2}$, X.-C. Zhang ${ }^{1}$ \\ ${ }^{1}$ State Key Laboratory of Systematic and Evolutionary Botany, Institute of Botany, Chinese Academy of Sciences (CAS), \\ Beijing 100093, China.E-mail: zhangxc@ibcas.ac.cn
}

${ }^{2}$ Myanmar Floriculturist Association, Yangon 11201, Myanmar.E-mail: thetyunwe@gmail.com

Key words: Hymenophyllum, Pan-Himalaya, taxonomic revision, flora.

Summary. The present account deals with the filmy fern of genus Hymenophyllum from the Pan-Himalaya, as a precursor of the ongoing "Flora of Pan-Himalaya" project, which aims to update the taxonomy of the vascular plants from the Himalayas and adjacent mountainous regions. More than one hundred specimens of Hymenophyllum especially that grown in the Pan-Himalaya deposited in the China National Herbarium (PE) have been carefully examined, in comparison with the collections from the Himalayas kept in European herbaria (K, BM, and E). The morphology and anatomy of each specimen were studied and photographed. As a result, ten species were recognized and described in detail, key to species, photography illustrations of plant habit, leaf shape and margin, lamina cells and veinlets, and sori are provided to facilitate correct identification of plants. According to the most recent classification system of the filmy ferns, the genus Mecodium is no longer accepted, although the leaf margins of Mecodium are all entire. Hymenophyllum barbatum, $H$. denticulatum, $H$. exsertum, $H$. levingei, and $H$. simosianum belong to subgenus Hymenophyllum; $H$. corrugatum, $H$. longissimum, $H$. polyanthos belong to subgenus Mecodium; $H$. badium and H. javanicum belong to subgenus Globosa. It is noticed that Hymenophyllum species often distribute in forests of middle to high altitudes from 2000-3000(4000) $\mathrm{m}$ in the Himalayas. Among these, Hymenophyllum corrugatum and H. longissimum are endemic species to China, while $H$. levingei is globally threatened.

\section{Таксономические исследования плауновидных и папоротников из Гималаев и прилегающих регионов (I): Hymenophyllum (Hymenophyllaceae)}

\author{
Т. Ю. Нве ${ }^{1,2}$, С.-Ч. Жан ${ }^{1}$ \\ ${ }^{1}$ Государственная ведущая лаборатория систематики и эволющионной ботаники, Институт ботаники, \\ Китайская Академия наук (КАН), Пекин 100093, Kuтай. E-mail: zhangxc@ibcas.ac.cn \\ ²Acсоциация иฺветоводов Мьянма, Янгон 11201, Мьянма. E-mail: thetyunwe@gmail.com
}

Ключевые слова: пангималайский регион, таксономическая ревизия, флора, Hymenophyllum.

Аннотация. Сообщение посвящено пленчатолистным папоротникам рода Hymenophyllum из Гималаев и прилегающих регионов и представляет собой первый этап проекта "Flora of Pan-Himalaya”. Целью данного проекта является получение новых данных по систематике сосудистых растений из Гималаев и прилегающих горных регионов. Более ста видов Hymenophyllum из пангималайского региона, хранящихся в Китайском Национальном Гербарии (РЕ), были внимательно изучены и сравнены с коллекциями из Гималаев, хранящимися в европейских гербариях (K, BM, Е). Морфология и анатомия каждого образца были детально изучены, сделаны фотографии. В результате работы мы признаем десять видов. Приводятся их подробное описание, 
ключ для определения видов, фотографии, иллюстрирующие особенности растений, форму листьев и край, клетки листовой пластинки, жилкование и сорусы, для облегчения правильной идентификации растений. В соответствии с последней системой классификации пленчатолистных папоротников род Mecodium больше не принимается, несмотря на цельный край листьев у Mecodium. Hymenophyllum. barbatum, H. denticulatum, H. exsertum, H. levingei и H. simosianum относятся к подроду Hymenophyllum; H. corrugatum, H. longissimum, H. polyanthos относятся к подроду Mecodium; H. badium и H. javanicum относятся к подроду Globosa. Отмечается, что виды Hymenophyllum часто распространены в лесах на средних и больших высотах - в Гималаях на 2000-3000(4000) м над ур. м. и выше. Среди них Hymenophyllum corrugatum и H. longissimuтаre являются эндемичными в Китае, а H. levingei находится под глобальной угрозой исчезновения.

\section{Introduction}

The family Hymenophyllaceae Link, or filmy ferns, is one of the largest basal families of leptosporangiate ferns and comprises about 600 species (Iwatsuki, 1990) in tropical, subtropical and temperate regions of both Old and New Worlds. Filmy ferns are mainly constrained in very humid tropical and subtropical mountain forests, since its thin leaf blades consist of one cell thick and lack stomata. They are very sensible to moisture conditions; therefore, its distribution is limited by habitats and can be used as indicator of environment. Traditionally, only two large genera, i.e. Hymenophyllum with bivalved involucres and Trichomanes with tubular involucres were recognized. The most recent classification delivered through molecular phylogenetic analysis recognized nine genera, of which, the genus Hymenophyllum is the largest of the family with about 250 species and is subdivided into ten subgenera, i. e. Hymenophyllum, Mecodium, Globosa, Sphaerocionium, Pleuromanes, Hymenoglossum, Fuciformia, Cardiomanes, Diploophyllum, and Myrmecostylum (Ebihara et al., 2006).

Taxonomic studies of Hymenophyllum in the last century were mainly of floristic accounts. Iwatsuki (1985) reported 22 species from Asia; Mehra and Bir (1964), Chandra (2000), Ghosh et al. (2004), Singh and Panigrahi (2005), and Fraser-Jenkins (2008, 2010) studied those of the Indian subcontinent. The numbers of recognized species are five from Nepal (Iwatsuki 1988; Thapa 2002), but four were accepted by Fraser-Jenkins et al. (2015); six species from Bhutan by Fraser-Jenkins et al. (2009); six species from Myanmar by Dickason (1947) and 22 species from China by Liu et al. (2013). In the present revision, the morphological and anatomical characters of Hymenophyllum species from the PanHimalaya preserved in the China National Herbarium (PE) at Beijing were carefully studied during the one-year CAS-TWAS scholarship post-doctoral research conducted by the senior author. Altogether 10 species of three subgenera of Hymenophyllum from the Pan-Himalaya were described, illustrated and mapped. This is also a precursor of the ongoing "Flora of Pan-Himalaya" project.

\section{Material and methods}

\section{Study area}

The Pan-Himalaya (the Himalaya and adjacent regions) forms a natural geographic unit, from the Wakhan Corridor and northeastern Hindu Kush eastwards to the Hengduan Mountains by ways of Karakorum and the Himalayas. This region covers the northern corner of Afghanistan, northern Pakistan, northern India, Nepal, Bhutan, northern Myanmar, and southwest China (S Tibet, SE Qinghai, SE Gansu, W Sichuan, and NW Yunnan) (Fig. 1).

\section{Herbarium Specimens}

One hundred and eighteen specimens of Hymenophyllum especially that grown in the PanHimalaya deposited in the PE herbaria have been examined. The morphology and anatomy of each specimen were studied and photographed. The morpho-photographs of the plants were taken with a Nikon DXM 1200F camera connected to a stereomicroscope (Nikon SMZ 1000) and computer and measurement was done by D 3.10 (http:// www.nikoninstruments.com). Anatomical study was carried out with Leica DM 4000 B LED (Leica Microsystems, Wetzlar, Germany). The classification system of Hymenophyllum of this paper follows that of Ebihara et al. (2006).

\section{Taxonomic treament}

Key to the species of Hymenophyllum from Pan-Himalaya

1a. Sori on the tip of acroscopic segments of pinna; lips and margins of segment serrate or entire

2a. Margins of lamina distinctly toothed ......... 3

3a. Sori terminal on short acroscopic segments; lamina cell wall like beaded ...... 2. H.denticulatum

$3 b$. Sori on upper part of the fronds and on the ultimate segment 


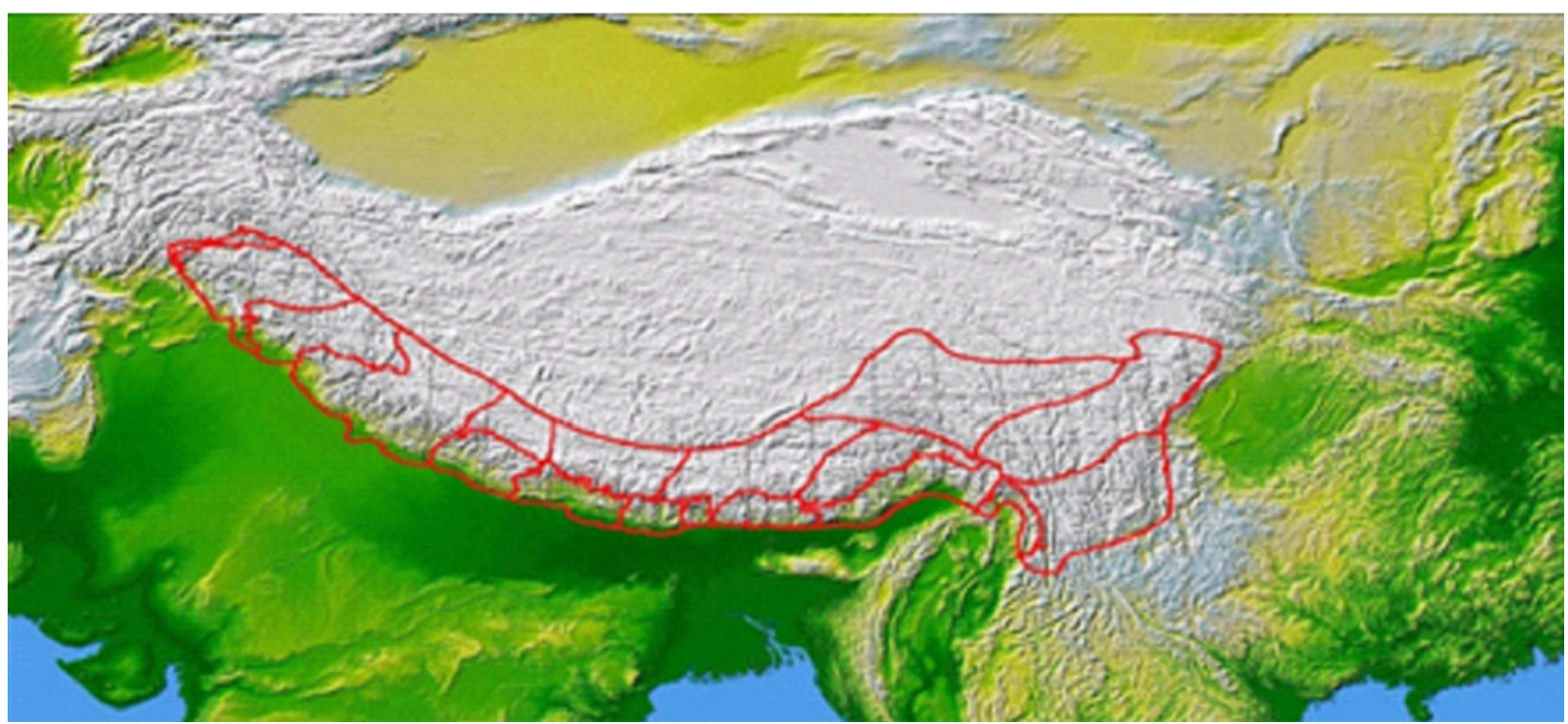

Fig. 1. Map of Pan-Himalaya.

4a. Lamina cells polygonal, elongate in outline, almost isodiametric 3. H. simonsianum

4b. Lamina cells polygonal, rounded in outline; not isodiametric

1. H. barbatum

2a. Margins of lamina entire

5a. Rachis, costa, and vein densely covered with laneolate multicellular palaea accessory winged ....

5. H. levingei

5b. Rachis, costa, and vein covered with multicellular linear hairs

4. H. exsertum

1a. Sori on the tip of ultimate segments of pinnae; lips and margins of segment usually entire, minutely serrate in some species 6

6a. Lamina cell wall thin and straight, sori lacking a thickened base 7

7a. Margin of ultimate segments deeply crisped, elliptic or narrowly linear ........... 6. H. corrugatum

7b. Margin of ultimate segments not deeply crisped

8a. Ultimate segments imbricate to adjacent one, closely spaced, apex obtuse or sometimes subtruncate

7. H. longissimum

8 b. Ultimate segments alternate, well spaced, apex blunt or truncate often retuse ...

8. H. polyanthos

6b. Lamina cell wall more or less thick, sori each with a thickened base

9a. Involucres subcircular or conic; lips flaring and broad; receptacle capitates 9. H. badium

9b. Involucres ovoid; lips round and subdeltoid; receptacle clavate to filiform ...... 10. H. javanicum

1. Hymenophyllum barbatum (Bosch) Baker, 1867, Syn. Fil. 68. - Leptocionium barbatum Bosch,
1867, Syn. Fil. 68. - Leptocionium flaccidum Bosch, 1861, Ned. Kruidk. Arch. 5(2): 149. - H. flaccidum (Bosch) Baker, 1868, Syn. Fil. 451. Hymenophyllum denticulatum var. flaccidum (Bosch) C. B. Clarke, 1880, Trans. Linn. Soc. London, Bot. 1(7): 438. - H. japonicum Miq., 1867, Ann. Mus. Bot. Lugd.-Bat. 3(6): 183. - H. khasianum Baker, 1874, Syn. Fil. (ed. 2): 464. - H. henryi Baker, 1889, J. Bot. 27(6): 176. - H. oxyodon Baker, 1890, J. Bot. 28(9): 262. - H. fastigiosum Christ, 1899, Bull. Herb. Boissier 7(1): 3. - H. omeiense Christ, 1906, Bull. Acad. Int. Géogr. Bot. 16(199-200-201): 101. H. spicatum Christ, 1906, Bull. Acad. Int. Géogr. Bot. 16(205-206): 235, f. s. n.- H. poilanei C. Chr. \& Tardieu, 1934, Bull. Mus. Natl. Hist. Nat., sér. 2 6(3): 289. - H. minutidenticulatum Ching \& P.S. Chiu, 1959, Fl. Reipubl. Popularis Sin. 2: 353. $-H$. whangshanense Ching \& P.S. Chiu, 1959, Fl. Reipubl. Popularis Sin. 2: 354. H. spinosum Ching, 1959, Acta Phytotax. Sin. 8(2): 162. - H. taiwanense De Vol, 1975, Fl. Taiwan 1: 120, pl. 40. - H. rufofibrillosum Ching \& Z.Y. Liu, 1983, Bull. Bot. Res., Harbin 3(4): 8, f. 7. H. suprapaleaceum Ching, 1983, Bull. Bot. Res., Harbin3(4): 9, f. 8. - H. urofrons Ching \& C.F. Zhang, 1983, Bull. Bot. Res., Harbin 3(3): 40.

Plants $2-15 \mathrm{~cm}$ tall. Rhizome long creeping, $0.2-0.4 \mathrm{~mm}$ in diam., brown to dark brown, or bronze, covered with stiff bronze unicellular hairs or subglabrous, with finely hairy roots. Stipes remote, 1.5-4 cm apart, dark brown or brown, filiform, 0.7-6 $\mathrm{cm} \times 1-1.5 \mathrm{~mm}$, with long bronze hairy throughout, hairs 3 to 4 cells, narrowly or slightly broad winged in the upper part or throughout. Rachis and costae 
brown, slightly zig-zag, densely covered with hairy on lower surface, hairs long, linear, multicellular, reddish brown; broadly winged throughout, wavy or crisped. Lamina bipinnatifid to tripinnatifid, ovate or oblong to oblong-lanceolate, $2-11 \times 1-4 \mathrm{~cm}$, membranous and semitransparent, glabrous, base gradually narrowing or broadly cuneate, apex obtuse to acute; pinnae 3-10 pairs, closely spaced, alternate, sessile, widely spreading, oblong or obovate to linear-subdeltoid, $0.5-2 \mathrm{~cm} \times 5-10 \mathrm{~mm}$, base unequally cuneate, apex rounded or acute; ultimate segments linear-oblong, 2-5 $\times 0.5-2 \mathrm{~mm}$, with 1 or 2 veinlets, margin subentire or serrate or serrulate, apex round, obtuse or slightly emarginate. Lamina cells polygonal, sometimes irregular in shape; cell walls slightly thick and wavy; marginal cell wall slightly wavy. Veins dichotomous, dark brown, free, obviously raised on the surface, densely hairy on
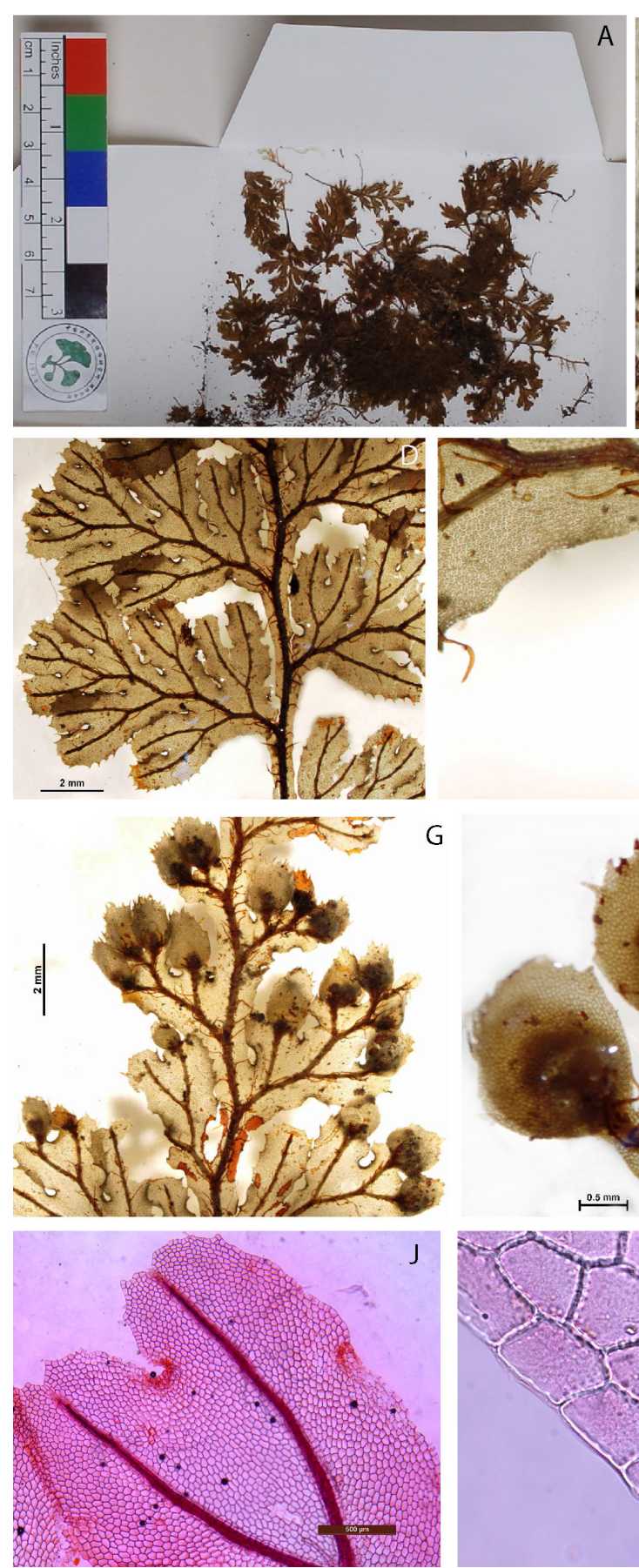
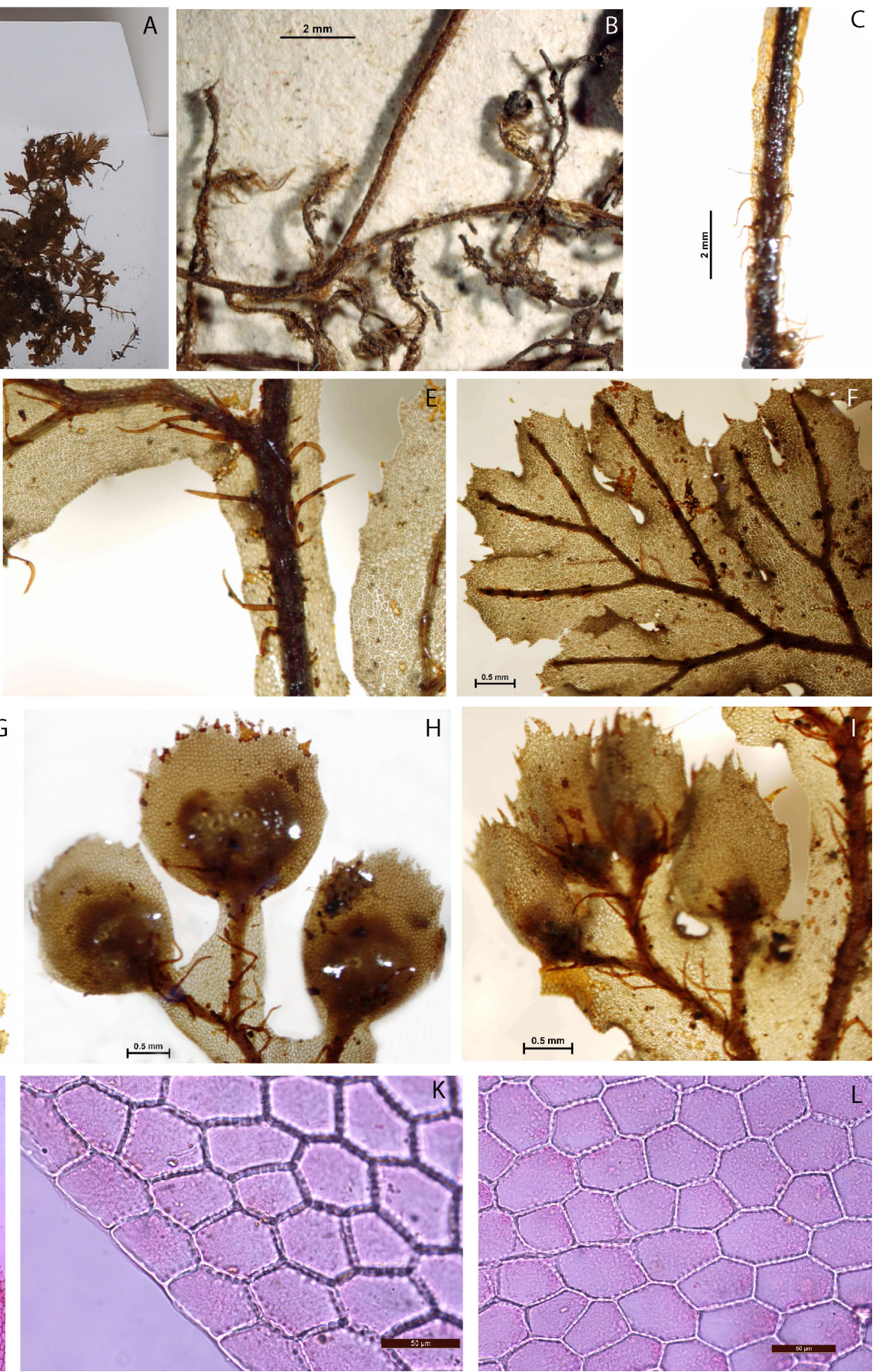

Fig. 2. Hymenophyllum barbatum (Bosch) Baker.: A - Frond, B - Rhizome, C - Stipe with winged and multicellular hairs, D - Part of frond, E - Rachis with hairy, F. Ultimate segments with serrate, G - Tip of fertile segment, H - Tip of fertile segment, I - Upper part of fertile frond, J - Pinna cell in outline, $\mathrm{K}$ - Marginal cells, L - Lamina cells. Fig. A-G, I-L: X. H. Jin et. al. DLT-ET 1015 (PE); Fig. H: W. M. Chu 5320 (PE). 
the lower surface. Sori on upper part of the frond, terminal on each short segment; involucres ovate to oblong, $0.8-1.8 \times 0.6-1.4 \mathrm{~mm}$, bilabiate almost to the base and hairy at base, lips slightly or deeply serrate and obtuse to rounded at apex; receptacles included (Fig. 2, 12A).

Distribution in Pan-Himalaya: Nepal, Bhutan, Northern India (Sikkim, Tehri Garhwal, Almora: Pindari), China (Yunnan, Gansu).

General distribution: Bhutan, China (Anhui, Fujian, Gansu, Guangdong, Guangxi, Guizhou, Hainan, Jiangxi, Sichuan, Taiwan, Yunnan, Zhejiang), India (Assam, Meghalaya, Khasia, Sikkim, Tehri Garhwal, Almora: Pindari), Japan (including Ryukyu Islands), Korea, Upper Myanmar, Nepal, Thailand (wide spread), Vietnam, Laos. This widespread and variable species has been mentioned by many authors. Moreover, Fraser-Jenkins (2010) reported that this species is endangered in India.

Habitat: On moss tree trunks or on wet rocks in subtropical or tropical evergreen forests, and near streams; at 760-1450 $\mathrm{m}$ regions.

Specimens examined: CHINA, YUNNAN, Gongshan, $1450 \mathrm{~m}$, Dulongjiang Exped. Team (X. H. Jin et al.) DLT-ET 1015; GANSU, Wenxian, 769 m, Bailongjiang Exp. 3502c.

2. Hymenophyllum denticulatum Sw., 1801, J. Bot. (Schrader) 1800(2): 100. - Trichomanes denticulatum (Sw.) Poir., 1808, Encycl. 8(1): 75. Didymoglossum denticulatum (Sw.) Hassk., 1857, Obs. Bot. 2: 16. - Leptocionium denticulatum (Sw.) Bosch, 1859, Ned. Kruidk. Arch. 4: 382.-Meringium denticulatum (Sw.) Copel., 1938, Philipp. J. Sci. 67(1): 42. - Trichomanes neesii Blume, 1828, Enum. Pl. Javae 2: 226. - Didymoglossum neesii (Blume) C. Presl, 1843, Hymenophyllaceae 23. - Hymenophyllum neesii (Blume) Hook., 1844, Sp. Fil. 1: 99. - Leptocionium neesii (Blume) Bosch, 1859, Ned. Kruidk. Arch. 4: 383.

Plants $2-4 \mathrm{~cm}$ tall. Rhizome long creeping, brown, slender, $0.2-0.3 \mathrm{~mm}$ in diam., sparsely with stiff, long, brownish multicellular hairs, glabrescent when old; rootlets densely covered with hairs. Stipes brown, $0.5-1.5 \mathrm{~cm} \times 0.4-0.5 \mathrm{~mm}$, slender, sparsely with long multicellular hairs, narrowly winged throughout, wing somewhat toothed. Rachis and costae dark brown, slightly zig-zag, winged throughout, wing broad, ca. $1.2 \mathrm{~mm}$ wide, crisped to varying degree with sharply dentate, sparsely hairy, hair brown, multicellular. Lamina bipinnate or tripinnatifid, subdeltoid-ovate or oblong-lanceolate, 2-6 $\times 1-2 \mathrm{~cm}$, narrowly cuneate or subtruncate at base, apex round; pinnae 4-7 pairs, closely spaced, alternate, sessile, ovate or oblong, 5-10 $\times 5-7 \mathrm{~mm}$, base unequally cuneate, apex round or obtuse, with 4-7 segments; ultimate segments $1.2-4.5 \times 0.5-1.2$ $\mathrm{mm}$, with a single veinlet, margin sharply toothed, apex obtuse or emarginated. Lamina cells elongated, polygonal; cell walls straight, rather thickened, appearing beaded; marginal teeth 3 or 4 cells wide at base; marginal cells wall thick and straight. Veins dichotomous, dark brown, obviously raised on the surface, hairy. Sori apical on short acroscopic segments, usually near rachis in upper part of fronds; involucres $2-2.5 \times 1-1.6 \mathrm{~mm}$, elliptic or tubular with accessory wings, base hairy, lips bilabiate nearly to the base, margin rounded to moderately acute with serrate; receptacle included (Fig. 3, 12B).

Distribution in Pan-Himalaya: Bhutan, China (South Tibet: Siang; Yunnan: Gongshan).

General distribution: Bhutan, Sri Lanka, China (Guangdong, Guangxi, Hainan, Taiwan, south Tibet, Yunnan), India (Assam, Meghalaya, Mizoram, Nagaland, Manipur, Arunachal Pradesh, Changlang), Indonesia (Java), Japan, Myanmar, Peninsular Thailand, Tokin, peninsular Malaysia, Philippines, Vietnam, east to Fiji, Borneo (Mt. Kinabalu, etc.), Sulawesi, Sumatra.

Habitat: On moss tree trunks or on wet rocks from 1900-2800 m, hilly regions.

Specimens examined: CHINA, YUNNAN, Gongshan: 1900 m, K. M. Feng 7344; 2400 m, s. n.; 2800 m, K. M. Feng 7943.

3. Hymenophyllum simonsianum Hook., 1861, Sec. Cent. Ferns 13, pl. 13. - Didymoglossum simonsianum (Hook.) Bosch, 1861, Ned. Kruidk. Arch. 5(2): 145.

Plants $4-10 \mathrm{~cm}$ tall. Rhizome short creeping, filiform, dark brown, $0.2-0.3 \mathrm{~mm}$ in diam., subglabrous or hairy, hairs linear, unicellular; rootlets with filiform, bronze, hairy. Stipes remote, 2-3 cm apart, dark brown, filiform, 1-2 cm long, ca. $0.1 \mathrm{~mm}$ wide, subglabrous or hairy, hairs deciduous, short, brown, unicellular, narrowly winged at apex. Rachis and costa dark brown, slightly zig-zag, sparsely hairy, broadly winged throughout, margin slightly serrate. Lamina pinnate to bipinnatifid, oblong to linear-lanceolate, $3-8 \mathrm{~cm} \times 1.5-2 \mathrm{~cm}$, membranous and semitransparent, glabrous; pinnae 4-8 pairs, $2-3 \mathrm{~mm}$ apart, alternate, sessile, obdeltoid to obovate, $1-1.5 \times 5-7 \mathrm{~mm}$, base acuminate, apex rounded to obtuse; ultimate segments oblong, 1.2$2 \times 2-4 \mathrm{~mm}$, with 1 to 2 veinlets, margin irregularly serrate, apex obtuse or truncate. Lamina cells 


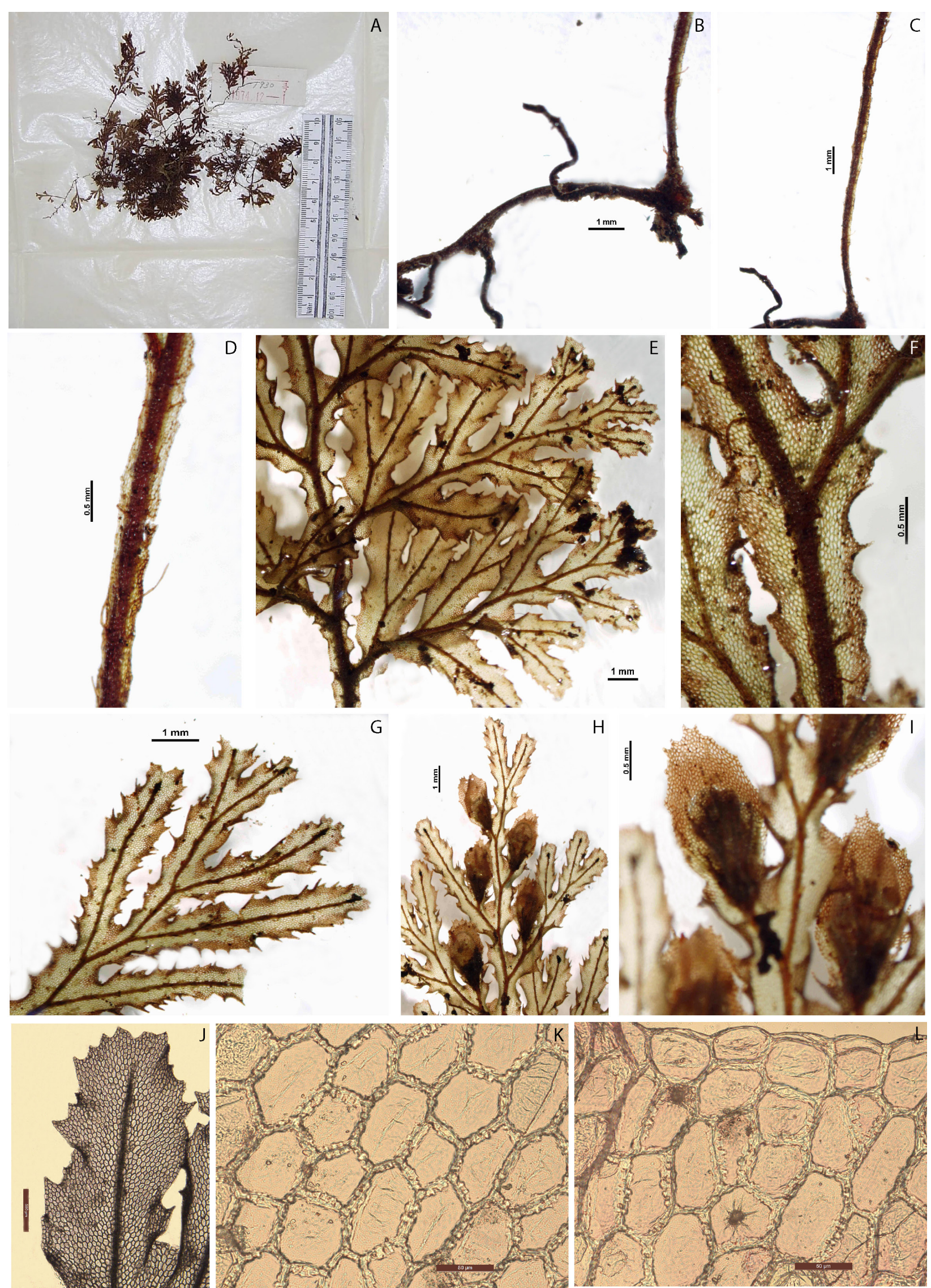

Fig. 3. Hymenophyllum denticulatum Sw.: A - Frond, B. Rhizome, C - Stipe, D - Stipe with narrowly winged and hairs, E - Part of frond, F - Rachis, G - Ultimate segments with serrated margin, H - Upper part of fertile frond, I Sorus, J - Pinna cell in outline, K - Lamina cells, L. Marginal cells. Hinan Team 1930 (PE). 
polygonal, elongate, almost isodiametric; cell walls slightly thick, coarsely pitted; marginal cells with cross-walls at right angles to the margin. Vein dichotomous, dark brown, obviously raised on each surface, hairy on lower surface, hairs clubshaped, brown. Sori terminal on ultimate segments; involucres oblong to oval, $2.5-3.4 \times 2-2.7 \mathrm{~mm}$, bilabiate, hairy at base, hairs club-shaped, lips irregularly denticulate; receptacle included (Fig. 4, 12C).

Distribution in Pan-Himalaya: Bhutan, East Nepal, India (Sikkim, Darjeeling), China (Xizang: Zayu, Medog; Yunnan: Gongshan).

General other distribution: China (Taiwan, Xizang), India (Kameng).

Habitat: On mossy tree trunks or rocks in dense forest at $1900-2800 \mathrm{~m}$ regions.

Specimens examined: CHINA, XIZANG, Zayu: 2400 m, Qinghai-Tibet Team. 73-784; Zayu:
Cibagou, $2500 \mathrm{~m}$, X. C. Zhang 4948; Medog: 2200 m, Qinghai-Tibet Team 74-4918; YUNNAN, Gongshan: 1900 m, K. M. Feng 7344; 2300 m, K. M. Feng 17442; 2800 m, K. M. Feng 794.

4. Hymenophyllum exsertum Wall. ex Hook., 1844, Sp. Fil. 1: 109, pl. 38 A. - Mecodium exsertum (Wall. ex Hook.) Copel., 1938, Philipp. J. Sci. 67(1): 23. - Hymenophyllum austrosinicum Ching, 1936, Hong Kong Naturalist 7(1): 87. - H. delavayi Christ, 1905, Bull. Soc. Bot. France: Mem. 1: 11. - H. gardneri Bosch, 1859 [1858], Ned. Kruidk. Arch. 4: 417.

Plants epiphytic, 3-8 $\mathrm{cm}$ tall. Rhizome long creeping, brown, filiform, wiry, sparsely hairy, hairs light brownish to bronze, multicellular or subglabrous; rootlets with finely root. Stipes remote, 1-2 $\mathrm{mm}$ apart, brown, filiform, $1-6 \mathrm{~cm} \times 0.3-0.5$ $\mathrm{mm}$, hairy throughout, hairs up to $2 \mathrm{~mm}$ long,
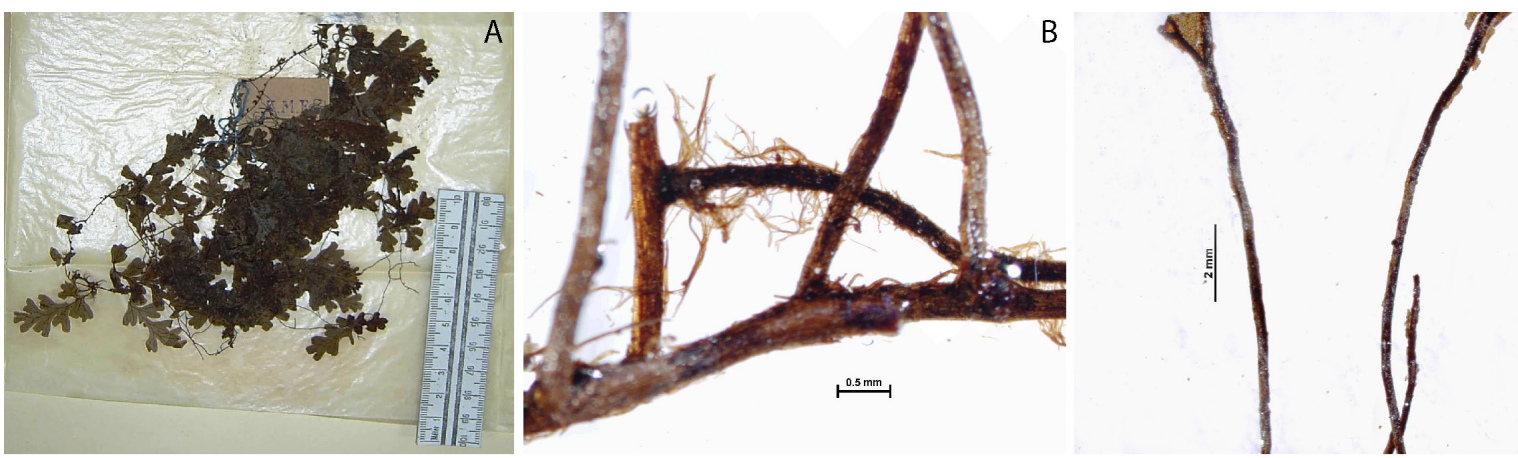

C
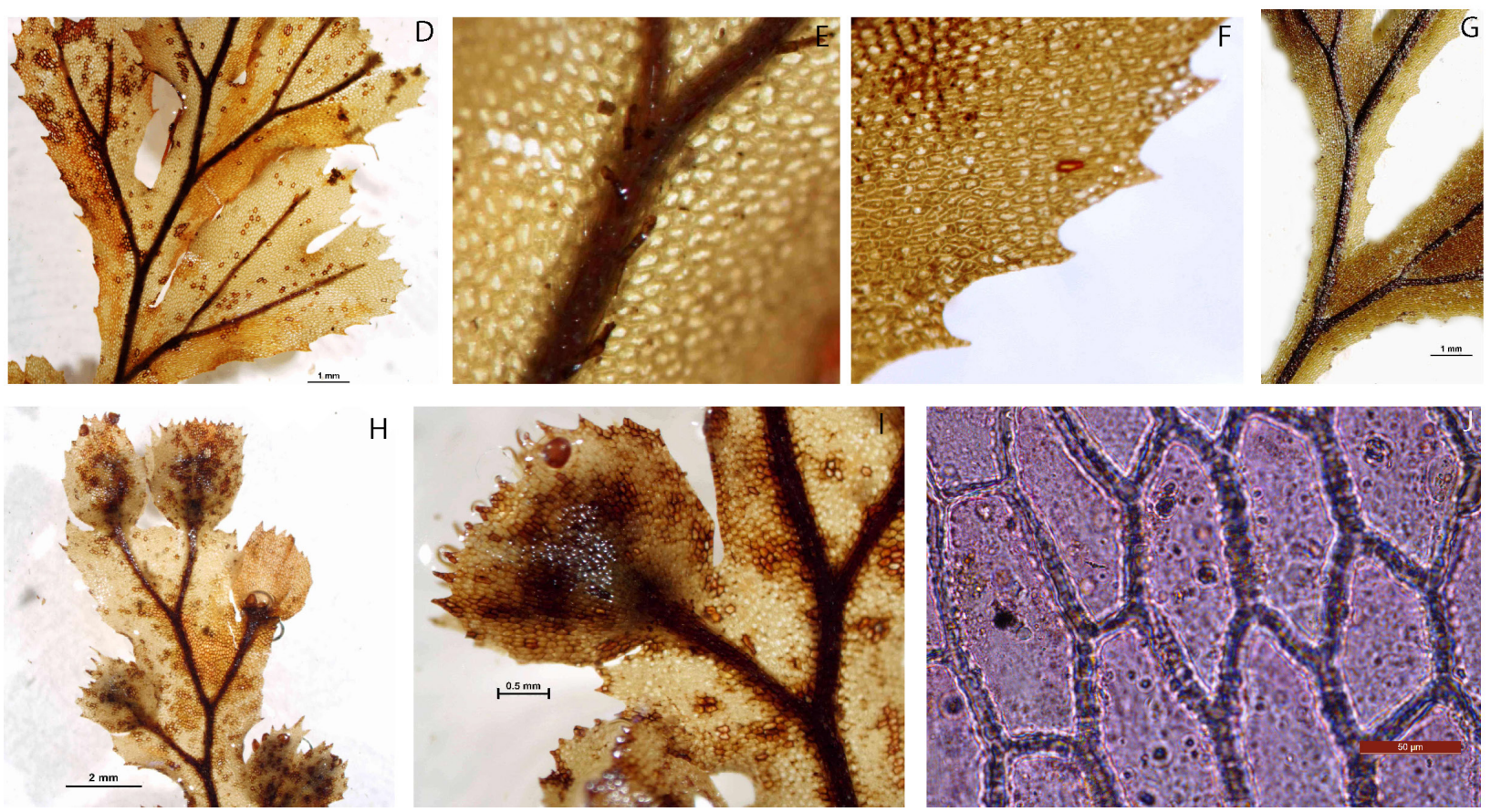

Fig. 4. Hymenophyllum simonsianum Hook.: A - Frond, B - Rhizome, C - Stipe, D - Part of frond, E - Vein with club-shaped hairs, F - Ultimate segments with serrated margin, $\mathrm{G}$ - Rachis with serrated margin, $\mathrm{H}$ - Upper part of the frond with sori, I - Sorus, J - Lamina cells. K. M. Feng 9443 (PE). 
multicellular, brown; winged on the upper part or nearly wingless. Rachis and costae prominent, black, hairy throughout like stipe, more densely on the lower surface; winged throughout, up to $1 \mathrm{~mm}$ broad, nearly flat, wavy or crispy. Lamina bipinnate to tripinnatifid, lanceolate, oblong or ovate, 3-12 $\times$ 1-4 cm, membranous, base acuminate, apex obtuse; pinnae 3-10 pairs, sessile, alternate, spreading, closely spaced, sometimes overlapping, glabrous, oblong to oblong-lanceolate, or triangular-ovate, slightly falcate, 4-16 × 5-13 mm, parted, base decurrent, apex round to moderately acute; pinnules 2-4 pairs, sessile, alternate, zig-zag, closely spaced, glabrous, obovate, $5-8 \times 3-5 \mathrm{~mm}$, base cuneate, apex round; ultimate segments simple or forked, linear-oblong, $1-2.8 \times 0.8-1 \mathrm{~mm}$, with a single veinlet, entire and flat, obtuse at apex. Lamina cells polygonal, unequal in shaped; cell walls slightly thickened and wavy; marginal cells wall elongate and wavy. Veins dichotomous, slightly raised on each surface, dark brown, zig-zag, with acicular hairs on each surface. Sori on upper parts of fronds; tip of the ultimate segment of pinna; involucres circular to oval, bivalvate, cleft to the base, $1-1.4 \mathrm{~mm}$ long, base hairy, lips equal, entire and often with teeth; receptacles slender, included (Fig. 5, 12D).

Distribution in Pan-Himalaya: Bhutan, W, C and E Nepal, India (Sikkim, Darjeeling, Subansiri, Tirap, TehriGarhwal, Chamoli, Almora: Pandari, Ghakuri, Dgawali, Pithoragaph: Didihat, Chamba: Dalhousie, PanJoulla), China (Xizang: Dingjie, Medog, Nyalam; Sichuan: Yanyuan; Yunnan: Deqin).

General distribution: Bhutan, Sri Lanka, China (Fujian, Guangdong, Hainan, Hong Kong, Sichuan, Taiwan, Yunnan, Xizhang), Himalaya, India (throughout mountainous regions, Himalchal Pradesh, Uttar Pradesh, Sikkim, Darjeeling, Meghalaya, Khasia Hills, Manipur, central and southern parts of India), Cambodia, Laos, Peninsular Malaysia, Upper Myanmar, Nepal, Thailand, Vietnam.

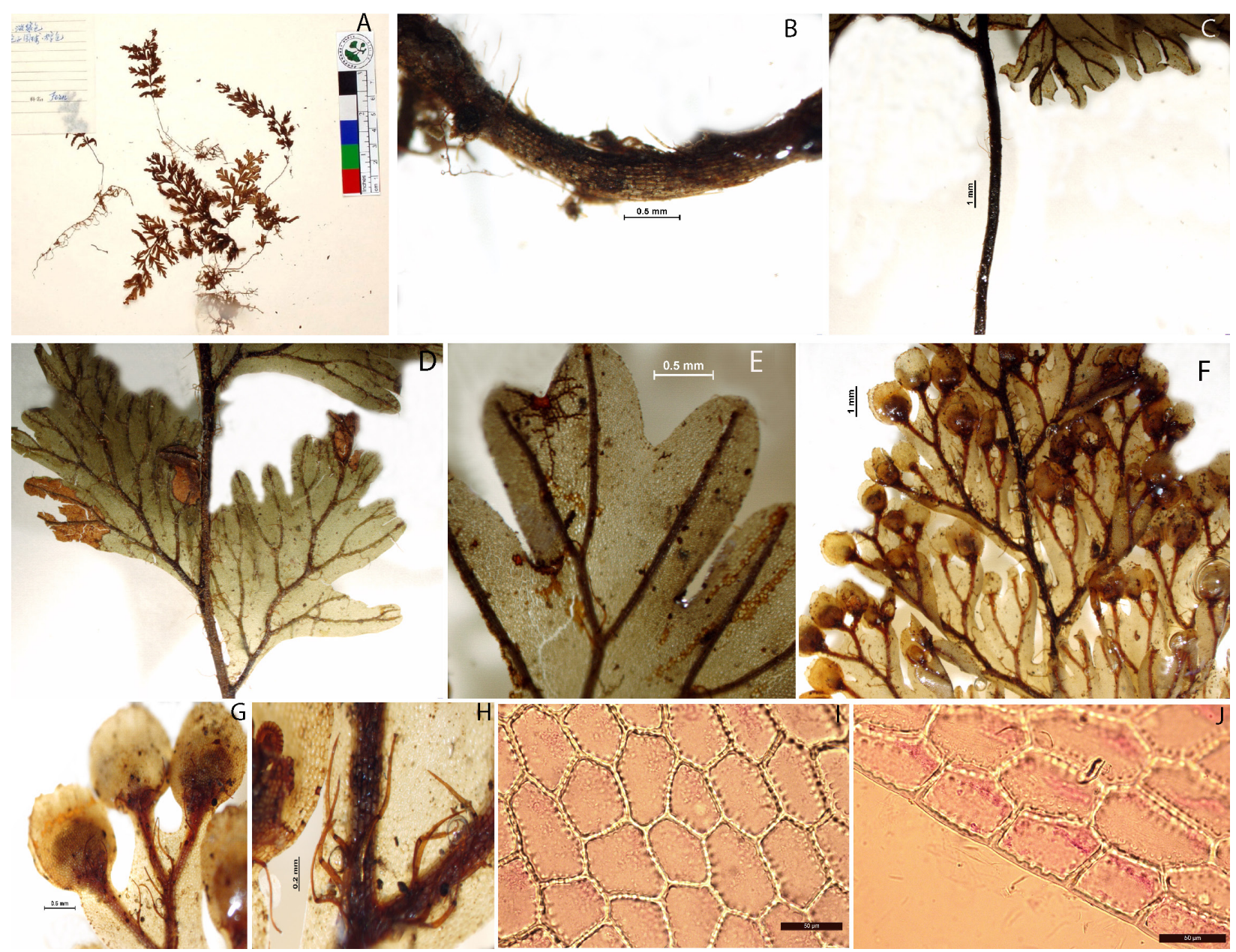

Fig. 5. Hymenophyllum exsertum Wall. ex Hook.: A - Frond, B - Rhizome, C - Stipe, D - Part of frond, E - Ultimate segments, $\mathrm{F}$ - Fertile frond, $\mathrm{G}$ - Sorus, $\mathrm{H}$ - Vein with multicellular hairs, I - Lamina cells, J - Marginal cells. D.D. Tao 821 (PE). 
Habitat: On tree trunks or on mossy rocks in dense forests mid or high altitude; at 2000-3900 m regions.

Specimens examined: CHINA, SICHUAN: Yanyuan: 3900 m, Tibetan Exp. Team 12769; XIZANG: s. n. 75-614; 2300 m, Qinghai-Tibet group (Vegetative team) 4476; Dingjie: $2400 \mathrm{~m}$, Tibetan Exp. Team 5604; 2500 m, Tibetan Exp. Team 5576; Medog: 2000 m, W. L. Chen 14545; 2400 m, B. S. Li, S. Z. Cheng 4400; 2400 m, B. S. Li, S. Z. Cheng 5223; Nyalam: 2400 m, Y. T. Chang, K. Y. Lang 4405; 2600 m, B. S. Li, H. Li 14172; 2800 m, Y. T. Chang, K. Y. Lang 3269; YUNNAN, Deqin: 3300 m, K. M. Feng 6403; Gongshan, Dulongjiang, X. C. Zhang et al. 8162 .

5. Hymenophyllum levingei $C . B$. Clarke, 1880 , Trans. Linn. Soc. London, Bot. 1(7): 439, t. 49, f. 3. - Mecodium levingei (C.B. Clarke) Copel., 1947, Gen. Fil. (Copeland): 33.

Plants $4-5 \mathrm{~cm}$ tall. Rhizome long creeping, filiform, ca. $0.3 \mathrm{~mm}$ in diam., brown, mostly glabrous except the base of the stipe; rootlets sparse hairy, hairs unicellular, septate, reddish brown. Stipes remote, 1-2 cm apart, brown, filiform, 1-4 cm long, subglabrous, or with lanceolate multicellular paleae at apex, palea up to 5 cell rows, tapering to the apex; wingless. Rachis and costae brown, narrowly winged throughout, densely covered with lanceolate, multicellular paleae on both surface. Lamina 1-pinnate to bipinnatifid, green-brown, flat, linear to narrowly lanceolate, 2.5$6.5 \times 1-2 \mathrm{~cm}$, membranous, glabrous, base decurrent, apex acuminate; pinnae $6-8$ pairs, $3-4 \mathrm{~mm}$ apart, alternate, sessile, slightly oblique, ovate, 3-8.3 $\times$ 2-4.8 mm, base decurrent, apex obtuse, glabrous; ultimate segments simple or slightly forked, less than $1 \mathrm{~mm}$ apart, linear-oblong, $1-2.6 \times 0.5-0.9 \mathrm{~mm}$, with a single veinlet, with sparse teeth at margin, apex obtuse or sometimes shallow notch. Lamina cells hexagonal, mostly equal in shaped; cell walls slightly thickened and straight; marginal cells wall thin and straight. Veins dichotomous, free, slightly raised on each surface, deep and bright brown, with dense lanceolate multicellular paleae. Sori on upper parts of fronds, 2-5 per apical on the long ultimate segments of pinna; involucres subcircular or oval, $1.2-1.5 \times 1.2-1.3 \mathrm{~mm}$, bilabiate, deeply cleft nearly at the base, lips entire or slightly tooth; receptacles included (Fig. 6 \& 13A).

Distribution in Pan-Himalaya: Bhutan; Northern India (Sikkim); E. Nepal (rare), China (Yunnan: Gongshan; Xizang: Nyalam).
General distribution: Bhutan, E. Himalaya, China (Sichuan, NW Yunnan, Xizang), N. India (Sikkim).

Habitat: On rocks near rivers, or on tree trunks in forests in mid to high altitude; at 2500-3000 m region. This is one of the globally threatened species as mentioned by C. R. Fraser-Jenkins (2012).

Specimens examined: CHINA, YUNNAN, Gongshan: 3000 m, C. W. Wang 67117; XIZANG, Nyalam: 2500 m, F. Ludlow et al. 7010.

6. Hymenophyllum corrugatum Christ, 1903, Bull. Herb, Boissier, sér. 2, 3(6): 508. - Mecodium corrugatum (Christ) Copel., 1938, Philipp. J. Sci. 67(1): 21. - Hymenophyllum corrugatum var. elongatum Christ, 1906, Bull. Acad. Int. Géogr. Bot. 16 (199-200-201): 101. - Mecodium corrugatum var. elongatum (Christ) H.S. Kung, 1988, Fl. Sichuanica 6: 144. - Mecodium gongboense Ching, 1983, Fl. Xizang. 1: 47.

Plants $7-9 \mathrm{~cm}$ tall. Rhizome long creeping, dark brown nearly black, 2-2.6 $\mathrm{mm}$ in diam., with sparse brown short hairs or glabrous, rootlets with sparsely hairy. Stipes remote, $1-1.5 \mathrm{~cm}$ apart, black to reddish brown, filiform, $2-4 \mathrm{~cm} \times 0.2-0.35 \mathrm{~mm}$, subglabrous, wingless or narrowly winged at the base of the lamina. Rachis and costae blackish to reddish brown, winged throughout, wing strongly crisped, glabrous. Lamina bipinnate to tripinnatifid, triangular-ovate, 5-9 $\times 1-2.5 \mathrm{~cm}$, membranous, glabrous, base subcordate, apex obtuse; pinnae 8-12 pairs, closely spaced, alternate, subsessile, linear to lanceolate, $1.5-5 \mathrm{~cm} \times 5-8 \mathrm{~mm}$, base unequally cuneate, apex acuminate; pinnules 5-14 pairs, closely spaced, alternate, sessile, oblong to ovate, 4-6 $\times 3-4 \mathrm{~mm}$, base decurrent, apex obtuse; ultimate segments simple or forked, elliptic or narrowly linear, $1-2.5 \times 0.5-0.8 \mathrm{~mm}$, margin sharply crisped, apex obtuse. Lamina cells polygonal, somewhat irregular in shape but near vein a little elongate; cell walls thin and straight; marginal cells elongate, thin and straight. Vein dichotomous, free, slightly raised on each surface, brown, glabrous, with single veinlet. Sori on upper parts of frond, terminal on ultimate segments; involucres subcircular, oblong or conic, $0.8-1.6 \times 0.9-1.7 \mathrm{~mm}$, lips bivalvate, entire or sometimes wavy at apex (Fig. $7 \& 13 \mathrm{~B}$ ).

Distribution in Pan-Himalaya: China (Sichuan: Maoxian, Baoxing; Xizang: Medog).

General distribution: China (Hubei, Sichuan, Xizang).

Habitat: On rocks or on tree trunks in dense forest at $3000-4000 \mathrm{~m}$ regions. This species is endemic in China. 

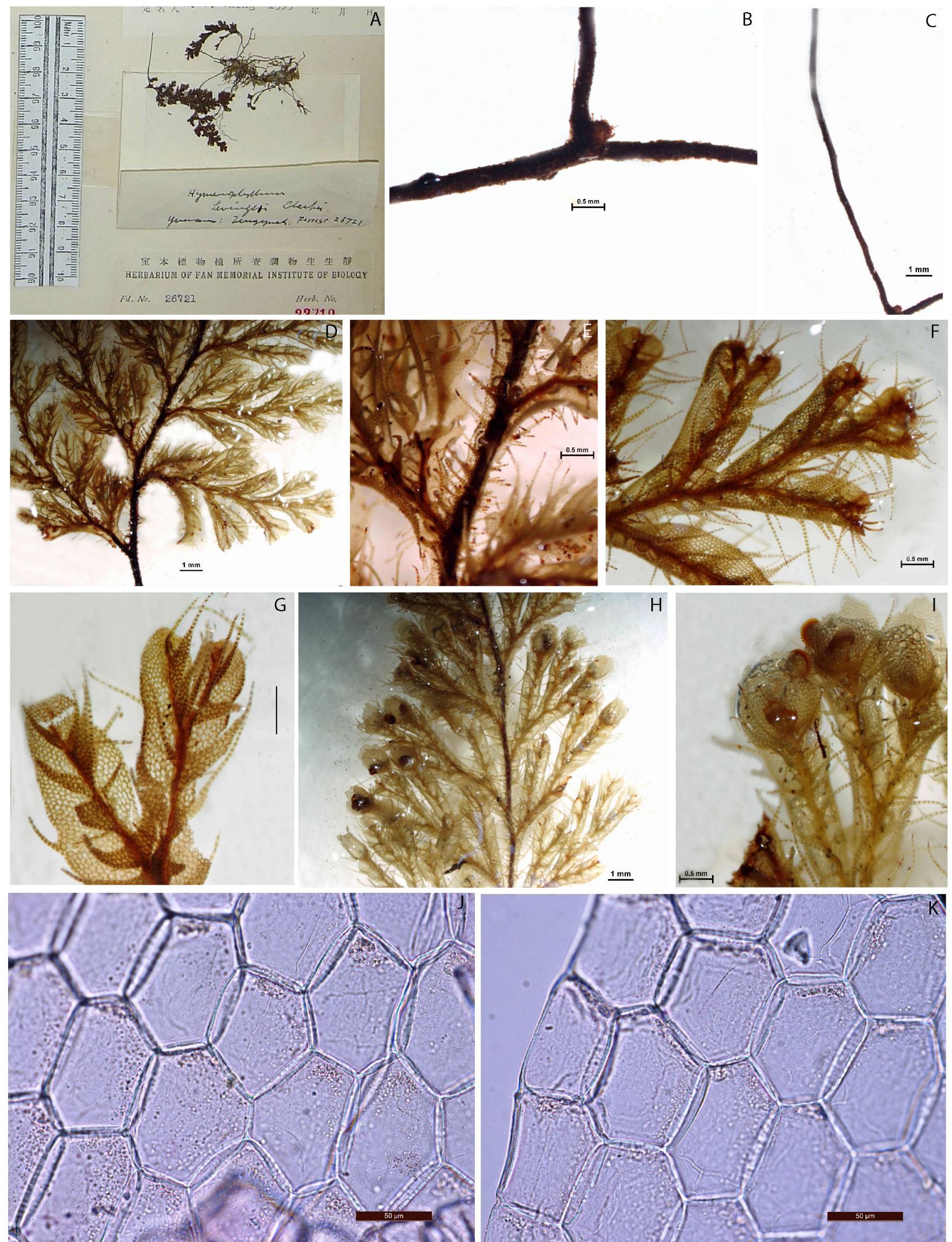

Fig. 6. Hymenophyllum levingei (C. B. Clarke) Copel.: A - Frond, B. Rhizome, C - Stipe, D - Part of frond, E Rachis with lanceolate multicellular palaea accessory winged, F - Pinna, G - accessory winged attached to the lower part of the pinna, H - Fertile part of the frond, I - Sorus, J - Lamina cells, K -Marginal cells. G. Forrest 26721(PE). 
Specimens examined: CHINA, SICHUAN, Baoxing: K. L. Chu 3293 (Mecodium corrugatum var. elongatum); Maoxian: 3000 m, s. n. 11028 (M. corrugatum); s. n., K. L. Chu 3293 (M. corrugatum); XIZANG, Medog: 3300 m, B. S. Li, S. Z. Chen 2063 (M. corrugatum); Molo: $4000 \mathrm{~m}$, F. Ludlow et al. 4371 (M. gongboense) [TYPE].

7. Hymenophyllum longissimum (Ching \& P. S. Chiu) K. Iwats., 1985, J. Fac. Sci. Univ. Tokyo, Sect. 3, Bot. 13: 522. - Mecodium longissimum Ching \& P.S. Chiu, 1959, Fl. Reipubl. Popularis Sin. 2: 350. - M. lineatum Ching \& P.S. Chiu, 1959, Fl. Reipubl. Popularis Sin.2: 351.

Plants $10-30 \mathrm{~cm}$ tall. Rhizome long creeping, filiform, $0.2-0.4 \mathrm{~mm}$ in diam., dark brown, with sparsely multicellular hairs, bronze; rootlets with finely hairy. Stipes remote, $1-2 \mathrm{~cm}$ apart, brown, filiform, $2-8 \mathrm{~cm} \times 0.2-0.3 \mathrm{~mm}$, with bronze multicellular hairs at base, glabrous upward, nearly wingless or decurrently downwards at apex, wings slightly wavy. Rachis and costae brown, glabrous, slightly zig-zag, broadly winged throughout, ca. 1 mm on each side, upper part of wing slightly wrinkled. Lamina bipinnate to tripinnatifid; membranous and semitransparent, glabrous, narrowly linear to linearlanceolate, $6-15 \times 1-1.5 \mathrm{~cm}$, base acuminate, apex acuminate; pinnae 6-18 pairs, closely spaced or slightly imbricate to adjacent ones, alternate, sessile, oblong-ovate, 4-10 × 3-5 mm, base decurrent, apex obtuse; ultimate segments simple or usually forked, closely spaced or imbricate to adjacent ones, flat, oblong, $1-3 \times 1-1.2 \mathrm{~mm}$, with a single veinlet, margin entire or slightly wrinkled, obtuse at apex or sometimes subtruncate. Lamina cells polygonal, irregular in shape; cell walls thin and straight; marginal cells elongated, thin and straight. Veins dichotomous, free, brown, obviously raised on the surface, glabrous. Sori numerous, on upper parts of fronds, apical on short ultimate segments; segments broader than the involucres and slightly wrinkled, involucres circular or oval, $1.3-1.8 \times 1.2-1.9 \mathrm{~mm}$,
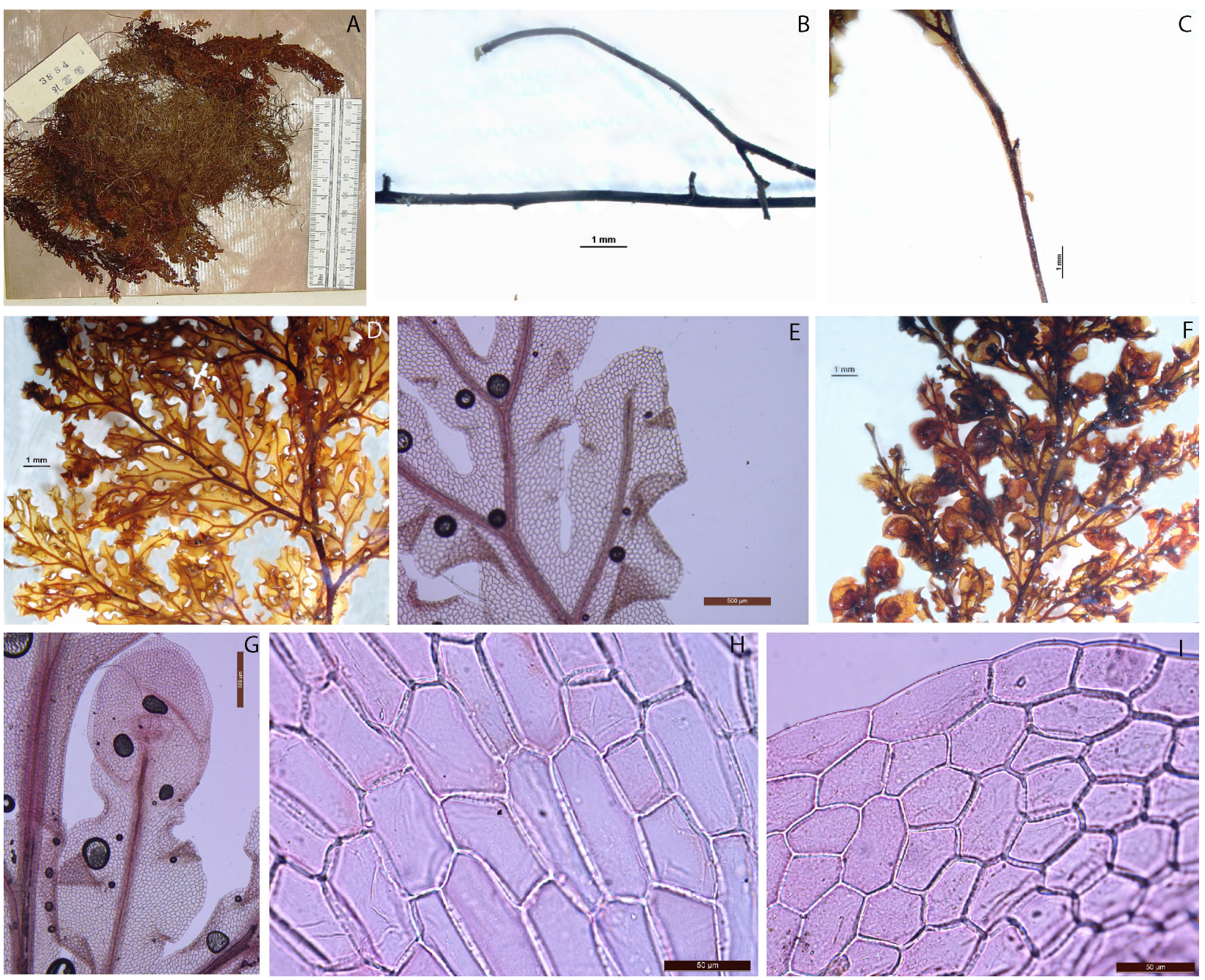

Fig. 7. Hymenophyllum corrugatum (Christ) Copel.: A - Frond, B - Rhizome, C - Stipe, D - Part of frond, E Ultimate segments, F - Fertile frond, G - Sorus, H - Lamina cells, I - Marginal cells. H. S. Kung 3884 (PE). 
bivalvate, deeply cleft to base, lips obtuse, entire or slightly wavy; receptacle included (Fig. 8 \& 13C).

Distribution in Pan-Himalaya: China (Yunnan: Weixi, Deqin; Xizang).

General distribution: China (Hubei, Sichuan, Xizang, NW Yunnan).

Habitat: On wet rocks or on tree trunks in forests; at 2000-3700 m regions.

Specimens examined: CHINA, YUNNAN, Weixi: 3400 m, K. M. Feng 4240 (Mecodium longissimum); 3500 m, K. M. Feng 3992 (M. longissimum); Deqin: $3200 \mathrm{~m}$, Qinghai-Tibet Team 1901 (M. lineatum); 3300 m, K. M. Feng 6403 (M. longissimum); 3500 m, C. W. Wang 69060 (M. lineatum); $3600 \mathrm{~m}, \mathrm{~K}$. M. Feng 5423 (M. lineatum); 3700 m, K. M. Feng 5191 (M. lineatum); Gongshan: $2000 \mathrm{~m}, \mathrm{C}$. W. Wang 67312 (M. lineatum); 2000 m, K. M. Feng 8640 (M. lineatum); $2500 \mathrm{~m}, \mathrm{C}$. W. Wang 6744 (M. lineatum); XIZANG, Nage: 3200 m, QinghaiTibet Team 74-3855 (M. lineatum); Zayu: 2900 m, Qinghai-Tibet Team 73-1031(M. lineatum); Dingjie:
2400 m, Qinghai-Tibet Team 6552 (M. lineatum); 2400 m, Qinghai-Tibet Team 5549 (M. lineatum).

8. Hymenophyllum polyanthos (Sw.) Sw., 1801, J. Bot. (Schrader) 1800(2): 102. - Trichomanes polyanthos Sw., 1788, Prodr. 137. - Mecodium polyanthos (Sw.) Copel., 1938, Philipp. J. Sci. 67(1): 19. - H. blumeanum Spreng., 1827, Syst. Veg. 4(1): 131. - Hymenophyllum himalaianum Bosch, 1861, Ned. Kruidk. Arch. 5(2): 156. - H. fecundum Bosch, 1861, Ned. Kruidk. Arch. 5(2): 153. - H. polyanthos var. minor Bedd., 1869, Ferns Brit. India pl. 306. H. alfredii Rosenst., 1925, Repert. Spec. Nov. Regni Veg. 22(606-608): 4. - H. botryoides Bosch, 1861, Ned. Kruidk. Arch. 5(2): 160. - Hymenophyllum costaricanum Bosch, 1861, Ned. Kruidk. Arch. 5(2): 161. - H. constrictum Hayata, 1914, Icon. Pl. Formosan. 4: 140, f. 80. - H. costaricanum var. emarginatum Rosenst., 1925, Repert. Spec. Nov. Regni Veg. 22(606-608): 4. - H. coreanum Nakai, 1926, Bot. Mag. (Tokyo) 40(473): 246. - Mecodium coreanum (Nakai) Seriz., 1971, J. Jap. Bot. 46(1):
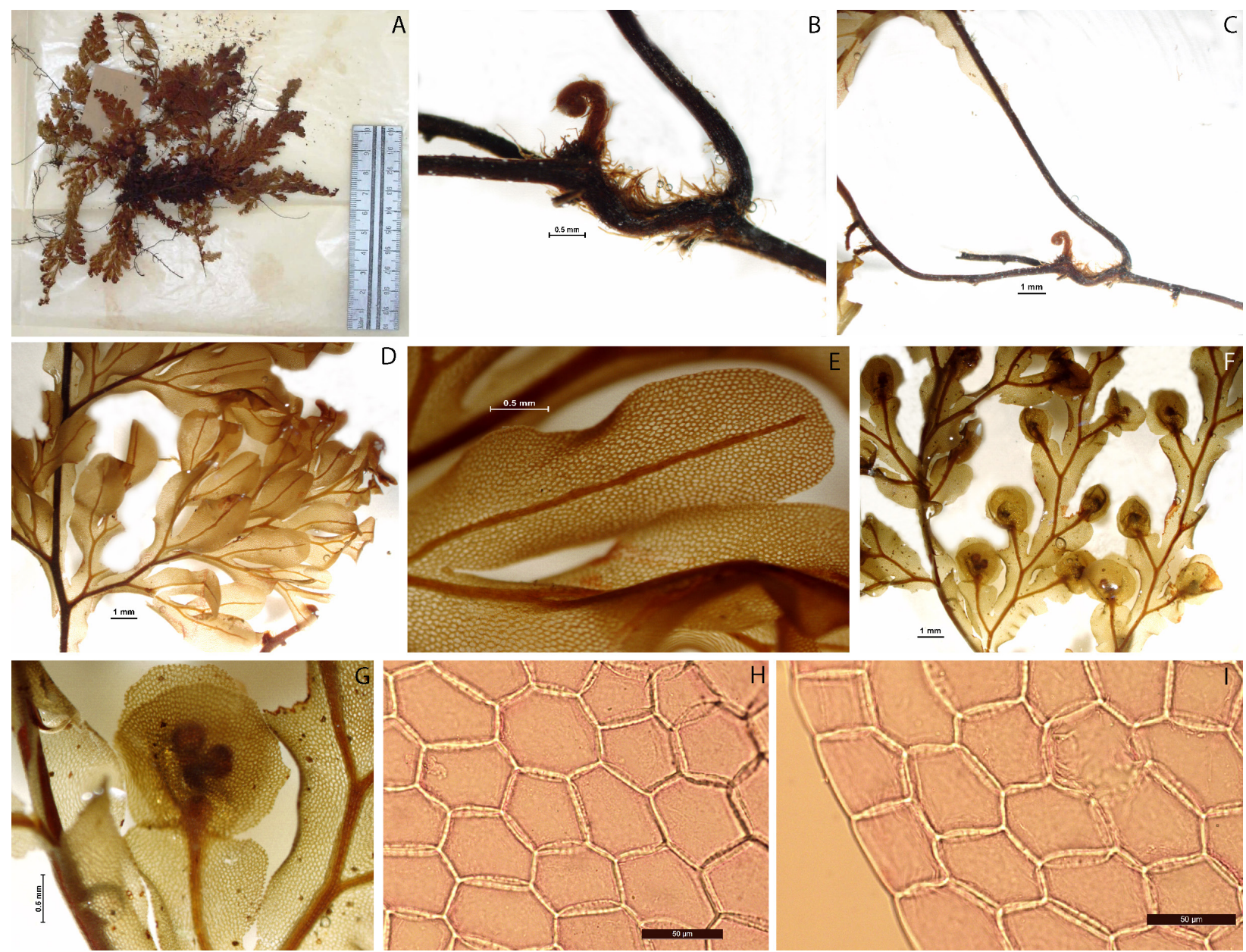

Fig. 8. Hymenophyllum longissimum (Ching \& P. S. Chiu) K. Iwats.: A - Frond, B - Rhizome, C - Stipe, D - Part of frond, E-Ultimate segments, F - Fertile frond, G - Sorus, H - Lamina cells, I - Marginal cells. K. M. Feng 3992 (PE). 
16. - H. hayatai Masam., 1936, Short Fl. Formos. 2.H. fujisanense Nakai, 1926, Bot. Mag. (Tokyo) 40(473): 249. - Mecodium fujisanense (Nakai) Sugim., 1951, Shokubutsu Kensakushi 1: 6. H. integrum Bosch, 1856, P1. Jungh. 1: 563. H. jalapense Schltdl. \& Cham., 1830, Linnaea 5: 619. - Mecodium mexiae Copel., 1941, Univ. Calif. Publ. Bot. 19(9): 294, t. 48. - Hymenophyllum mexiae (Copel.) C.V. Morton, 1968, Contr. U.S. Natl. Herb. 38(4): 173. - H. microsorum Bosch, 1861, Ned. Kruidk. Arch. 5(2): 155. - Mecodium microsorum (Bosch) Ching, 1959, Fl. Reipubl. Popularis Sin. 2: 143. - Hymenophyllum millefolium Schltdl. \& Cham., 1830, Linnaea 5: 620. H. osmundoides Bosch, 1861, Ned. Kruidk. Arch. 5(2): 164. - Mecodium osmundoides (Bosch) Ching, 1959, Fl. Reipubl. Popularis Sin. 2: 147, f. 10: 7. Hymenophyllum paniculiflorum C. Presl, 1843, Hymenophyllaceae 55. - Mecodium paniculiflorum (C. Presl) Copel., 1938, Philipp. J. Sci. 67(1): 19. - Hymenophyllum parallelocarpum Hayata, 1914, Icon. Pl. Formosan. 4: 141, t. 82. - H. punctisorum Rosenst., 1915, Hedwigia 56(4): 333. - H. tenellum D. Don, 1825, Prodr. Fl. Nepal. 12. - H. trichomano ides var. subalatum Rosenst., 1925, Repert. Spec. Nov. Regni Veg. 22(606-608): 4. - Mecodium acrocarpum Ching, 1959, Fl. Reipubl. Popularis Sin.2: 379. - M. acrocarpum (Christ) Christ ex Ching \& Chun, 1959, Fl. Reipubl. Popularis Sin.2: 146. - M. hainanense Ching, 1959, Acta Phytotax. Sin. 8(2): 161. - M. jinfoshanense Ching \& Z.Y. Liu, 1983, Bull. Bot. Res., Harbin 3(4): 10. M. kansuense Ching \& Y.P. Hsu, 1974, Fl. Tsinling. 2: 205. - M. likiangense Ching \& P.S. Chiu, 1959, Fl. Reipubl. Popularis Sin. 2: 352. M. lofoushanense Ching \& P.S. Chiu, 1959, Fl. Reipubl. Popularis Sin.2: 353. - M. lushanense Ching \& P.S. Chiu, 1959, Fl. Reipubl. Popularis Sin. 2: 352. - M. ovalifolium Ching \& P.S. Chiu, 1959, Fl. Reipubl. Popularis Sin.2: 352. M. szechuanense Ching \& P.S. Chiu, 1959, Fl. Reipubl. Popularis Sin.2: 353. - M. wangii Ching \& P.S. Chiu, 1959, Fl. Reipubl. Popularis Sin. 2: 351. - M. wenhsienense Ching \& Y.P. Hsu, 1974, Fl. Tsinling. 2: 205.

Plants $2-17 \mathrm{~cm}$ tall. Rhizome long creeping, brown or black, filiform, $0.2-0.3 \mathrm{~mm}$ in diam., with sparsely hairy, hairs brown, caducous; rootlets with densely long hairs. Stipes remote, $1-4 \mathrm{~cm}$ apart, columnar, $0.4-8 \mathrm{~cm}$ long, slender, wingless or narrowly winged to $1 / 3$ of the stipe, wings flat, entire. Rachis and costae dark brown, glabrous, narrowing winged to the base gradually broad upwards, wings flat, entire. Lamina bipinnate to quadripinnatifid, brown-green or brown, triangular-ovate, obovate, broadly lanceolate or linear, $2-13 \times 0.5-5 \mathrm{~cm}$, membranous, glabrous, largest in basal pinna and gradually tapering to upward, base cuneate, cordate, or rounded, apex acuminate or obtuse; pinnae 4-17 pairs, 1-4 $\mathrm{mm}$ apart, alternate, spreading, sessile, glabrous, oblong to ovate or obovate, the lower part of pinna oblong-ovate, $1-2.6 \times 0.5-1.5 \mathrm{~cm}$, base cuneate to unequally oblique, apex obtuse to acuminate; pinnules 3-4 pairs, alternate, wellspaced, 1-2 mm apart, sessile, oblique ovate to flabellate, 3-6 × 2-4 mm, base oblique cuneate, apex obtuse to truncate; ultimate segments $2-4$, alternate, very oblique, oblong-linear, $1-3 \times 0.3-0.5$ $\mathrm{mm}$, with 1 or 2 veinlets, margin entire, apex blunt or truncate, often retuse. Lamina cells polygonal, nearly isodiametric, irregular in shape; cell walls thin, straight; marginal cells nearly right angle to the margin, marginal cell wall slightly wavy. Veins dichotomous, obviously raised on both surfaces, dark brown, glabrous. Sori usually on upper parts of fronds, terminal on ultimate segments; involucres conic, $1.4-2.1 \times 0.8-1.6 \mathrm{~mm}$, bivalvate, cleft to the base, lips entire or toothed, obtuse or acute at apex; receptacles included (Fig. 9, 13D).

Distribution in Pan-Himalaya: Bhutan, India (Sikkim; Darjeeling, Kameng, Siang, Lohit, Almora, Pindari, Dwali, Khati. Pithoragaph), W., C. and E. Nepal, China (Gansu: Wenxian; Yunnan: Gongshan, Jianchuan, Lijiang, Weixi; Sichuan: Baoxing, Luding, Wenchuan, Yanbian; Xizang: Zayu, Dingjie, Medog, Nyalam, Xigaze).

General distribution: Bhutan, China (Anhui, Fujian, Gansu, Guangdong, Guangxi, Jiangxi, Hunan, Sichuan, Taiwan, Xizang, Zhejiang), India (throughout, Uttar Pradesh, Sikkim, Darjeeling Hills, Meghalaya; Nagaland, south and west India throughout in mountainous regions), Japan, Korea, Sri Lanka, Java, Malaysia, Myanmar, Philippines, Thailand (widespread), Laos, Sulawesi, Cambodia, Vietnam; America, Africa, Australia (Queensland), Marquesas islands, Madagascar. It is cosmopolitan; tropical, subtropical and temperate regions of the world.

Habitat: On tree trunks or on mossy rocks in shade, near the stream or some open places in lowlands and also at mid altitudes $750-3900 \mathrm{~m}$ regions.

Specimens examined: CHINA, GANSU, Kangxian: s. n. 1108 (Mecodium kansuense); Wenxian: $2390 \mathrm{~m}$, Whitewater River Exped. 138 (M. polyanthos); $2250 \mathrm{~m}$, L. Q. Li et al. 178 
(M. polyanthos); 2425 m, D. E. Boufford et al. (M. microsorum); Luding: 2650 m, K. Y. Lang, L. Q. 37803 (M. polyanthos); 2725 m, D. E. Boufford Li, Y. Ren 392 (M. polyanthos); Wenchuan: 2500 m, et al. 37814 (M. polyanthos); SICHUAN, s. K. Y. Lang, L. Q. Li, Y. Ren 1301 (M. polyanthos); loc., C. Pei 8267 (M. szechanense); Baoxing: Yanbian: 2700 m, Tibetan Exped. Team 11522 G. L. Chu 3473 (M. microsorum); C. S. Zhao (M. polyanthos); 2700 m, Tibetan Exped. Team 419 (M. polyanthos); 2200 m, J. Shu et al. 1011911438 (M. polyanthos); 2700 m, Tibetan Exped.

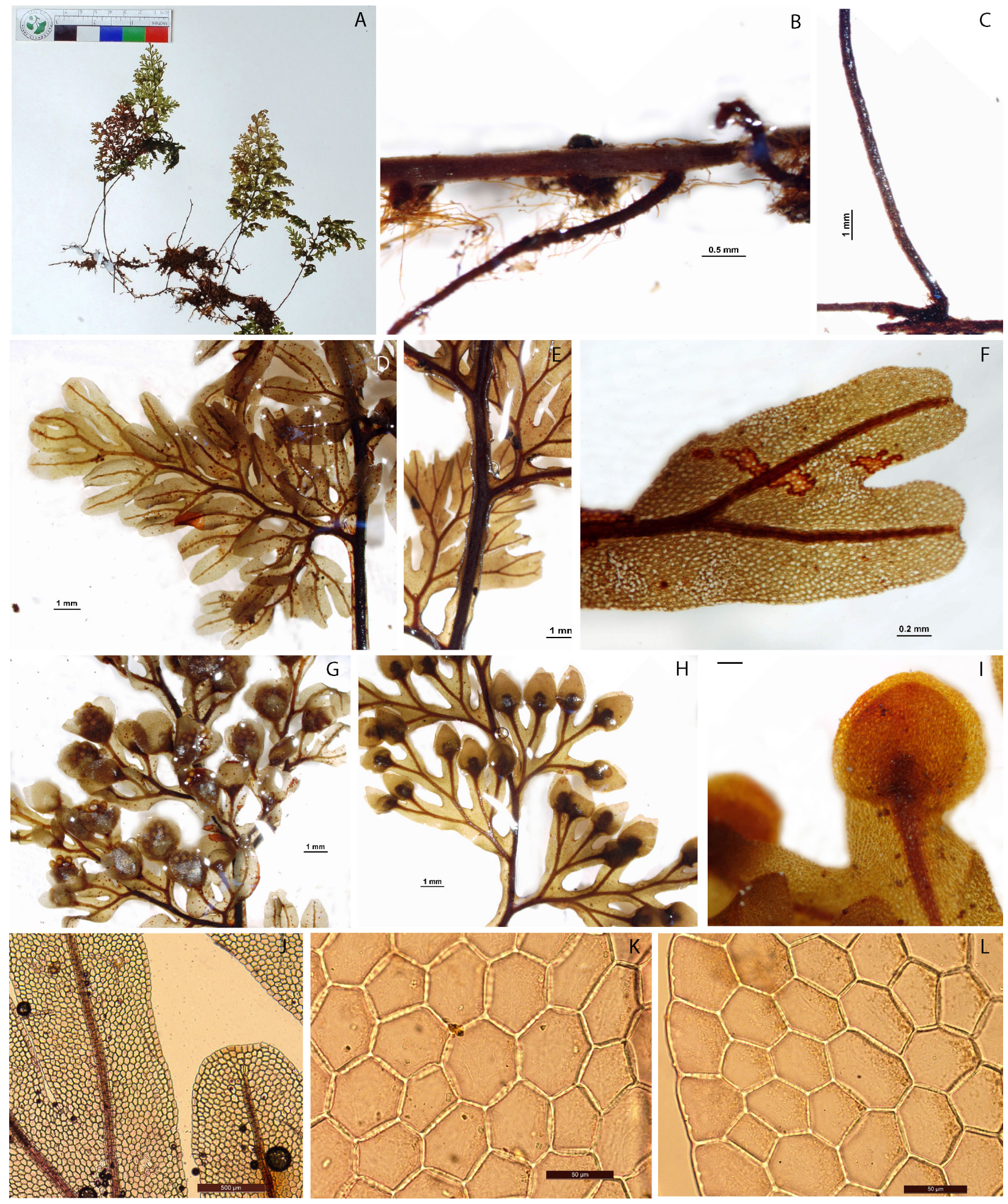

Fig. 9. Hymenophyllum polyanthos (Sw.) Sw.: A - Frond, B - Rhizome, C - Stipe, D - Part of frond, E-F - Ultimate segments, G-H - Fertile frond, I - Sorus, J - Lamina cells in out line, K - Lamina cell, L - Marginal cells. K. M. Feng 6404 (PE). 
Team 11522 (M. polyanthos); 2700 m, Tibetan Exped. Team 11438 (M. polyanthos); 3000 m, Tibetan Exped. Team 11699 (M. polyanthos); 3900 m, Tibetan Exped. Team 12769 (M. polyanthos); $3900 \mathrm{~m}$, Tibetan Exped. Team 12813 (M. polyanthos); YUNNAN, $2700 \mathrm{~m}, \mathrm{~K}$. M. Feng 9145 (Mecodium likiangense); Deqin: 3300 m, K. M. Feng 6404 (M. paniculiflorum); Gongshan: 2500 m, C. W. Wang 67344 (M. polyanthos); 3000 m, K.M. Feng 7163 (M. paniculiflorum); 3500 m, Tibetan Exped. Team 7779 (M. polyanthos); 3000 m, K. M. Feng 6936 (M. polyanthos); Jianchuan: R. C. Ching 24864 (M. ovalifolium); Lijiang: 2700 m, K. M. Fang 9152 (M. ovalifolium); Weixi: 3000 m. K. M. Feng 40047 (M. wangii); 3000 m, C. W. Wang 64599 (M. ovalifolium); 3500 m, C. W. Wang 64434 (M. ovalifolium); 3600 m, C. W. Wang 68872 (M. wangii); Yulongshan: $3200 \mathrm{~m}$, W. M. Chu \& Y. M. Feng 695 (M. himalianum); XIZANG, s. n. 1843 (M. paniculiflorum); Zayu: 2100 m, Z. C. Ni et al. 787 (M. polyanthos); Cibagou, $2800 \mathrm{~m}$,
X. C. Zhang 5003 (M. polyanthos); $2800 \mathrm{~m}$, Tibetan Exped. Team 73-776 (M. polyanthos); $2800 \mathrm{~m}, \mathrm{Z}$. C. Ni 73-610 (M. polyanthos); 2900 m, Z. C. Ni 73-776 (M. polyanthos); 3500 m, C.W. Wang 66092 (M.polyanthos); Dingjie: $2500 \mathrm{~m}$, Qinghai-Tibet team (Vegetation group) 3813a (Mecodium microsorum); Medog: 3000 m, B. S. Li, S. Z. Cheng 1844 (M. paniculiflorum); $750 \mathrm{~m}$, W. L. Chen 10948 (M. osmundoides); $1500 \mathrm{~m}$, South Tibet Exped. Team (STET) STET1889 (M. polyanthos); Zhamo road 60 km, 3000 m, South Tibet Exped. Team (STET) STET2427; 3000 m, Tibetan Exped. Team 74-3919 (M. polyanthos); Nyalam: 3300 m, Y. T. Chang, K. Y. Lang 3422, $3360 \mathrm{~m}$, Y. S. Chen et al. 769 (M. polyanthos); Salwin divide: G. Forrest 19937 (M. polyanthos); Xigaze: s. n. 75-617 (M. osmundoides).

9. Hymenophyllum badium Hook. \& Grev., 1828, Icon. Filic. 1(4): pl. 76. - H. javanicum var. badium (Hook. \& Grev.) C.B. Clarke, 1880, Trans. Linn. Soc.London, Bot. 1(7): 438.-Mecodium
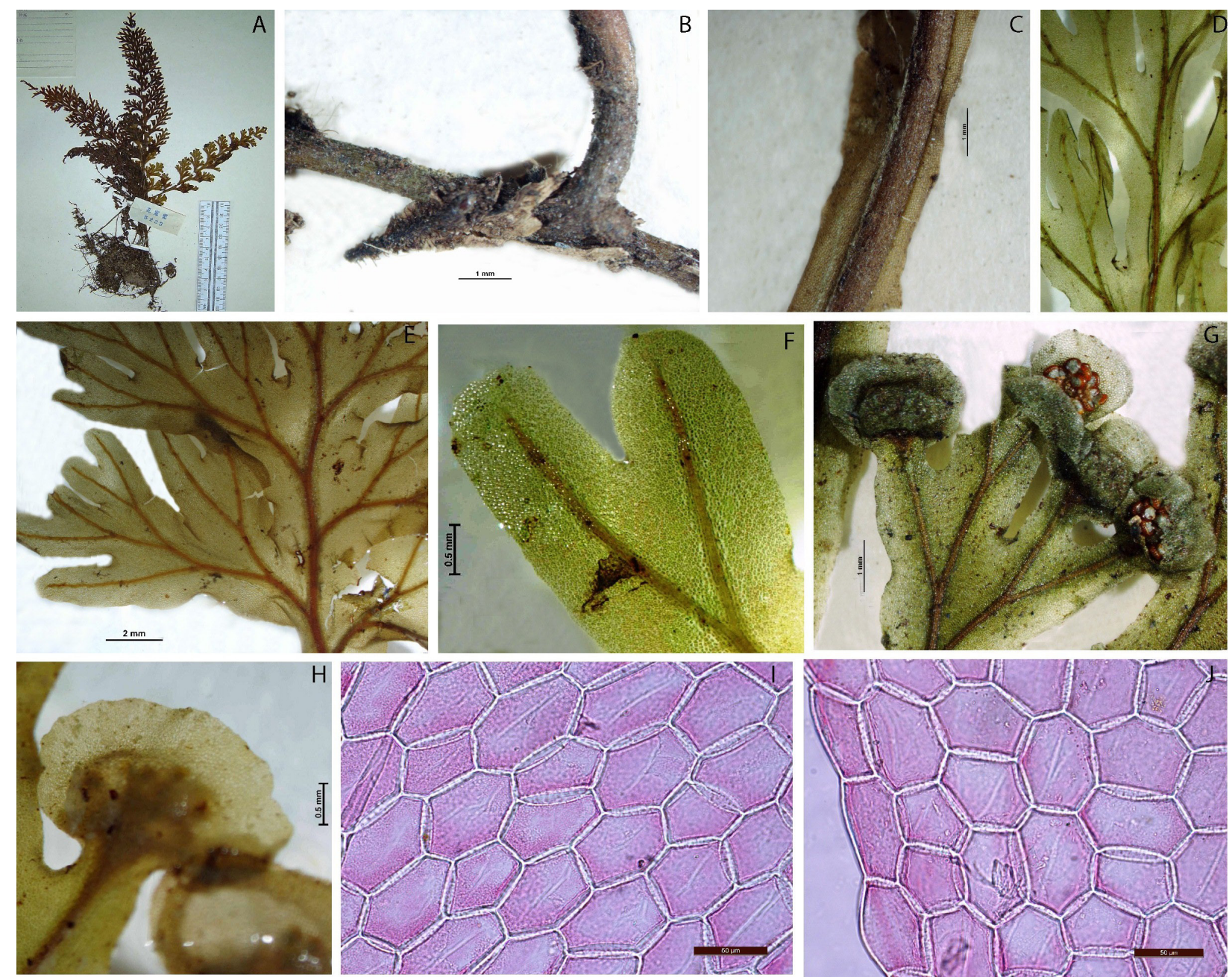

Fig. 10. Hymenophyllum badium Hook. \& Grev.: A - Frond, B - Rhizome, C - Stipe, D - Rachis, E - Part of frond, F - Ultimate segments, G - Fertile frond, H - Sorus, I - Lamina cells, J - Marginal cells. H. S. Kung 5233 (PE). 
badium (Hook. \& Grev.) Copel., 1938, Philipp. J. Sci. 67(1): 23. - Sphaerocionium badium (Hook. \& Grev.) C. Presl, 1843, Hymenophyllaceae 35. Hymenophyllum crispato-alatum f. remotipinnum Hayata, 1915, Icon. P1. Formosan. 5:257.-Mecodium crispatoalatum (Hayata) Copel., 1938, Philipp. J. Sci. 67(1): 23. - M. flexile (Makino) Copel., 1938, Philipp. J. Sci. 67(1): 23 - Hymenophyllum crispatoalatum Hayata, 1915, Icon. P1. Formosan. 5: 256. H. crispatum Wall. ex Hook. \& Grev., 1828, Icon. Filic. 1(4): pl. 77. - Mecodium crispatum (Wall. ex Hook. \& Grev.) Copel., 1938, Philipp. J. Sci. 67(1): 23. - Hymenophyllum cumingii Bosch, 1859, Ned. Kruidk. Arch. 4: 395. - H. flexile Makino, 1899, Bot. Mag. (Tokyo) 13(145): 45. H. latilobium Bonap., 1921, Notes Ptéridol. 13: 103.H. retusilobum Hayata, 1921, Icon. Pl. Formosan. 10: 72. - Mecodium propinquum Ching \& P.S. Chiu, 1959, Fl. Reipubl. Popularis Sin. 2: 350. M. tenuifrons Ching, 1959, Fl. Reipubl. Popularis Sin. 2:350.-Sphaerocionium macrocarpum C. Presl, 1843, Hymenophyllaceae 61. - Hymenophyllum macrocarpum (C. Presl) Bosch, 1858, Ned. Kruidk. Arch. 4: 395.

Plant $10-25 \mathrm{~cm}$ tall. Rhizome wiry, $0.4-0.8 \mathrm{~mm}$ in diam., dark brown, subglabrous; rootlets densely hairy, hairs filiform, dark brown, unicellular. Stipes remote, 1-2 cm apart, brown to dark brown, 4-9 $\mathrm{cm} \times 0.5-1 \mathrm{~mm}$, glabrous, winged throughout, gradually narrowing downwards, entire or more or less crisped. Rachis and costae broadly winged throughout, up to $1-1.3 \mathrm{~mm}$ broad, glabrous, entire, nearly flat or crisped, slightly zig-zag. Lamina tripinnatifid, oblong to lanceolate, ovate-lanceolate or ovate, 5-20 × 4-7 cm, membraneous, base acuminate, apex acute; pinnae $2-8$ pairs, closely spaced, alternate, spreading, subsessile, glabrous, obovate to lanceolate, $1.5-3.5 \times 1-2.5 \mathrm{~cm}$, base unequally cuneate, apex obtuse to acute or moderate acute; pinnules 3 or 4 pairs, closely spaced, alternate, sessile, spreading, oblong to oblong-lanceolate, 1-1.5 $\mathrm{cm} \times 4-8 \mathrm{~mm}$, base decurrent, apex obtuse; ultimate segments narrowly oblong, 3-5.8 $\times 1.3-1.9$ $\mathrm{mm}$, with single veinlet, apex round to obtuse, margin entire and flat. Lamina cells polyhedral, nearly isodiametric, irregular in shape; cell walls thin and straight; marginal cells irregular in shape, marginal cells wall thin and straight. Vein dichotomous, free, obviously raised on each surface, brown, glabrous. Sori apical on short ultimate segment; involucres subcircular or conic, $2-2.5 \times 2.5-3.5 \mathrm{~mm}$, bivalvate, lips flaring and broad, entire, sometimes slightly serrate or undulate; receptacle capitates, included (Fig. 10, 14A).
Distribution in Pan-Himalaya: Bhutan, India (Sikkim, Darjeeling, Kameng, Subansiri, Siang, Debang valley, Tirap, Uttarakhand [rare]), W., C. and E. Nepal; China (Yunnan: Gongshan, Lijiang, Weixi, south Tibet, Xizang: Medog, Dingjie).

General distribution: Bhutan, China (Fujian, Guangdong, Guangxi, Guizhou, Hainan, Hubei, Jiangxi, Sichuan, Taiwan, Yunnan), Indochina, India (Sikkim, Darjeeling, Uttarakhand [rare]), North to S. Japan, Ryukyu islands, C. and E. Nepal; southwards throughout Malesia, Myanmar, Malay Peninsula, Sri Lanka, Thailand (widespread), Vietnam, Borneo (Mt. Kinabalu), Sulawesi.

Habitat: On mossy tree trunk or on damp rocks and cliffs in dense tropical evergreen forest lower mid to higher altitude 1530-3500 m regions.

Specimens examined: CHINA, YUNNAN, R. C. Ching s. n. (Mecodium propinquum); Gongshan: K. M. Feng 8595 (M. tenuifrons); 2000 m, C. W. Wang 66963 (M. badium); 2000 m, C. W. Wang 66963 (M. tenuifrons); $2200 \mathrm{~m}$, S. Jiang et al. 8702 (M. badium); 2300 m, K. M. Feng 7444 (M. tenuifrons); 2500 m, K. M. Feng 7539 (M. tenuifrons); 3000 m, C. W. Wang 67249 (M. tenuifrons); $3400 \mathrm{~m}$, Tibetan Exped. Team 7782 (M. badium); Weixi: 3500 m, C. W. Wang 64434 (M. badium); XIZANG, $1600 \mathrm{~m}$, s. n. 2456 (M. badium); Medog: 1530 m, Tibetan Exped. Team 74-5092 (M. badium); 1600 m, W. L. Chen 14213 (M. badium); FLPH Tibet Exped. Team 12-09347 (M. badium); Dingjie: 2500 m, Tibetan Team (Vegetation Group) 3813A (Mecodium badium); EAST NEPAL, Rolwaling, khumbu: $2760 \mathrm{~m}$, C. S. Chang et al. NE0020535 (M. badium).

10. Hymenophyllum javanicum Spreng, 1827, Syst. Veg. 4(1): 132. - Mecodium javanicum (Spreng.) Copel., 1938, Philipp. J. Sci. 67(1): 20. - M. taiwanense Tagawa, 1940, Acta Phytotax. Geobot. 9(3): 141. - Hymenophyllum taiwanense (Tagawa) C.V. Morton, 1968, Contr. U.S. Natl. Herb. 38(4): 167.

Plants $5-15 \mathrm{~cm}$ tall. Rhizome long creeping, wiry, slender, ca. $0.5 \mathrm{~mm}$ in diam., with sparely brown hairs or nearly glabrous, with finely rootlet; rootlet densely covered with brown unicellular hairs. Stipes remote, $1-4 \mathrm{~cm}$ apart, $2-5 \mathrm{~cm} \times$ ca. $0.5 \mathrm{~mm}$, blackish, hairy at base, winged throughout, broader upwards and tapering to the base, entire or more or less crispy at margin, glabrous. Rachis and costae zig-zag, brown, sparsely hairy, club-shaped, brown, winged throughout, crispy. Lamina tripinnate or quadripinnatifid, 5-12 × 2-4 cm, broadly elliptic to ovate, acute at base, broadly at middle, apex acute 

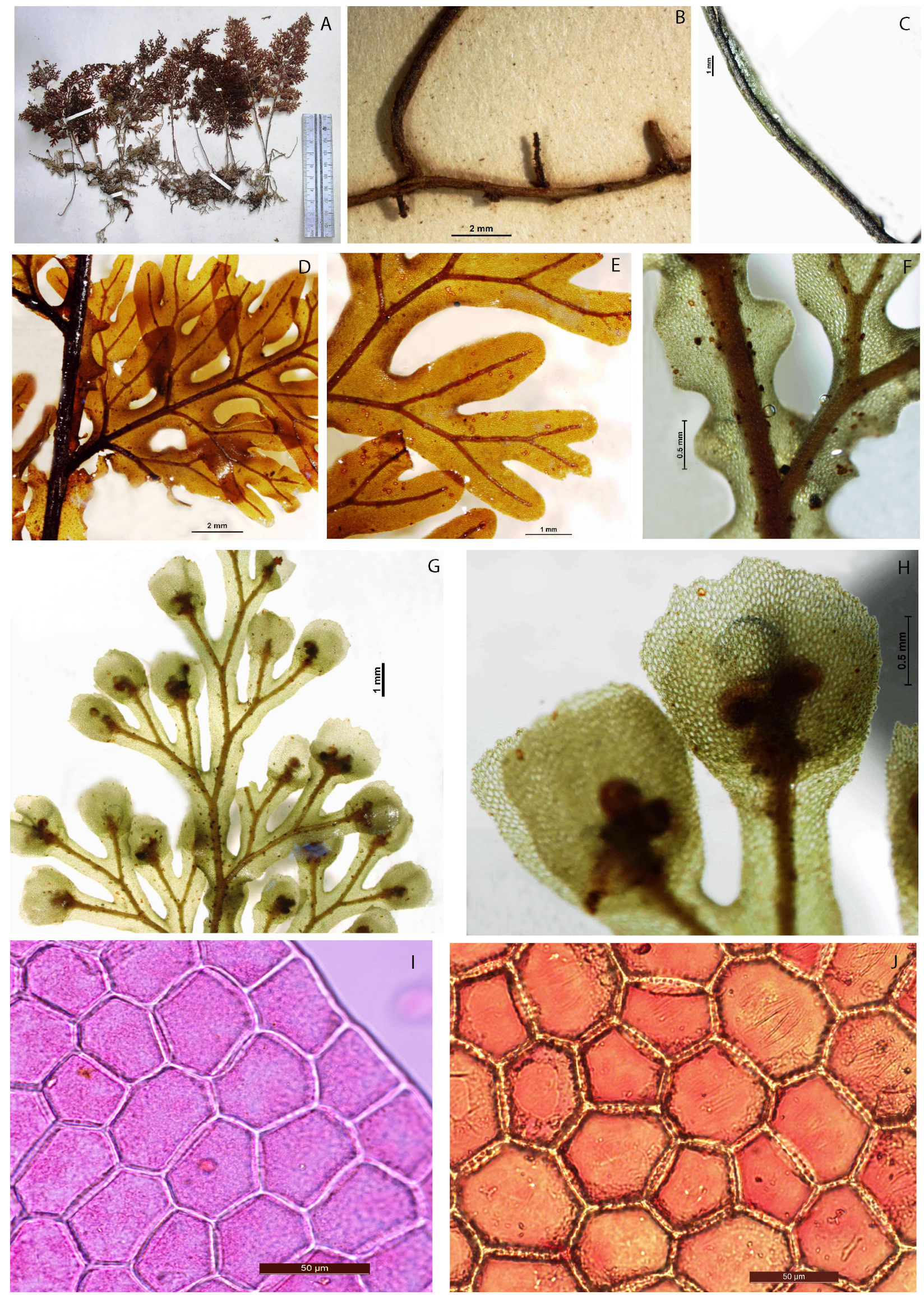

Fig. 11. Hymenohpyllum javanicum Spreng.: A - Frond, B - Rhizome, C - Stipe, D - Part of frond, E - Ultimate segments, F - Rachis, G - Fertile frond, H - Sorus, I - Marginal cells, J - Lamina cells. G. Forrest 20725 (PE). 

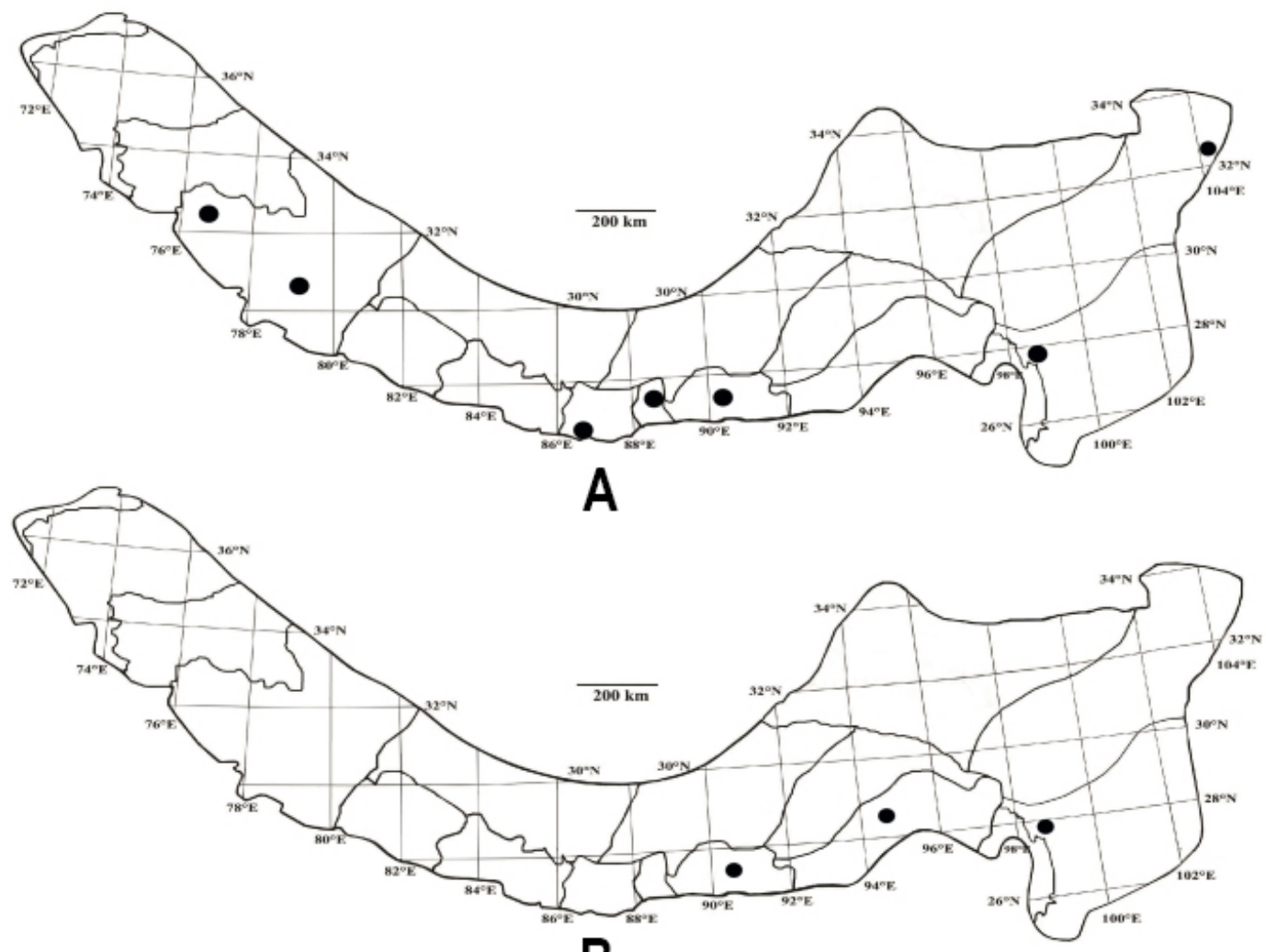

B
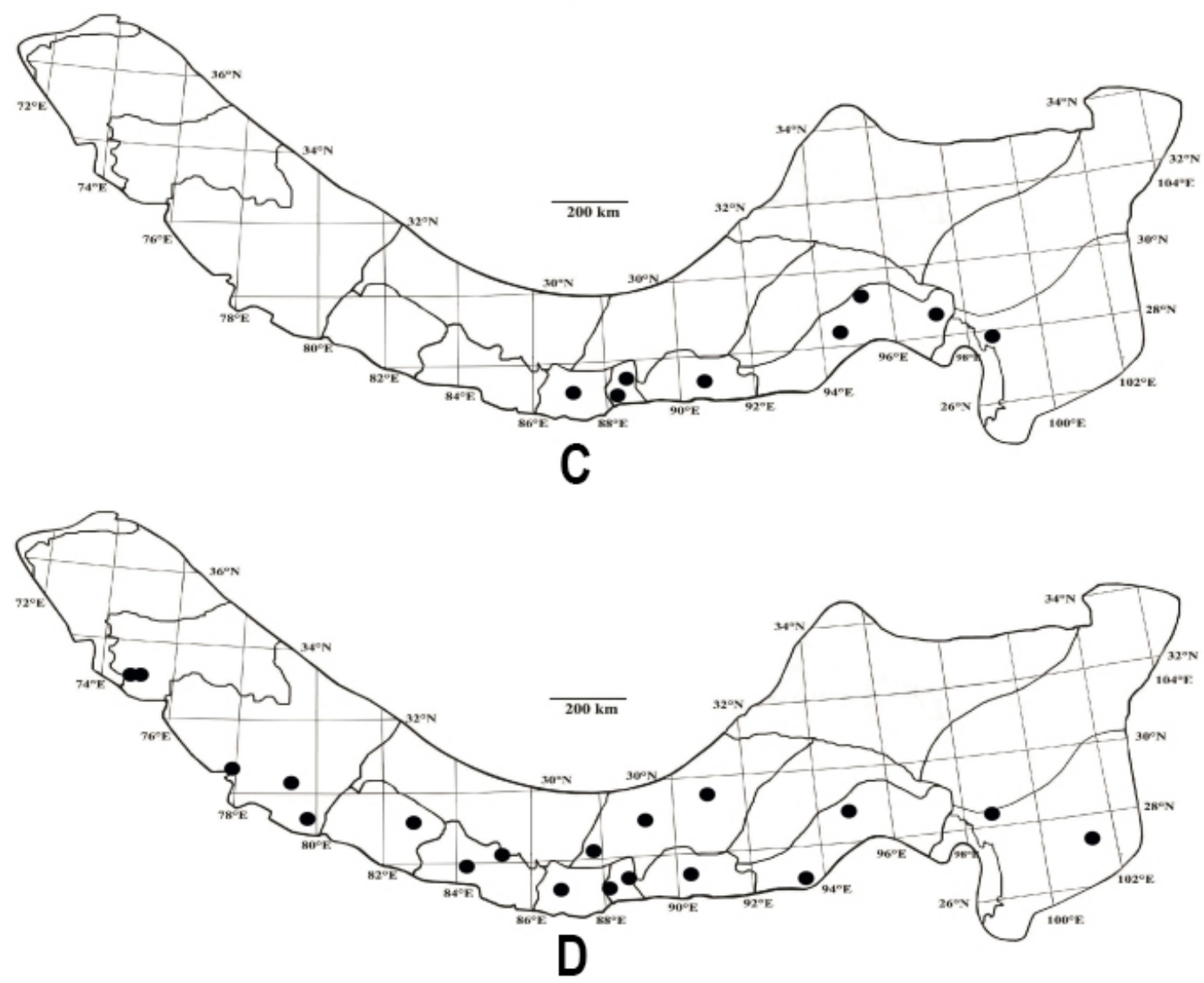

Fig. 12: Distribution of the Hymenophyllum in Pan Himalaya regions: a - Hymenophyllum barbatum (Bosch) Baker; $\mathrm{b}-H$. denticulatum Sw.; $\mathrm{c}-H$. simonsianum Hook.; d $-H$. exsertum Wall. ex Hook. 

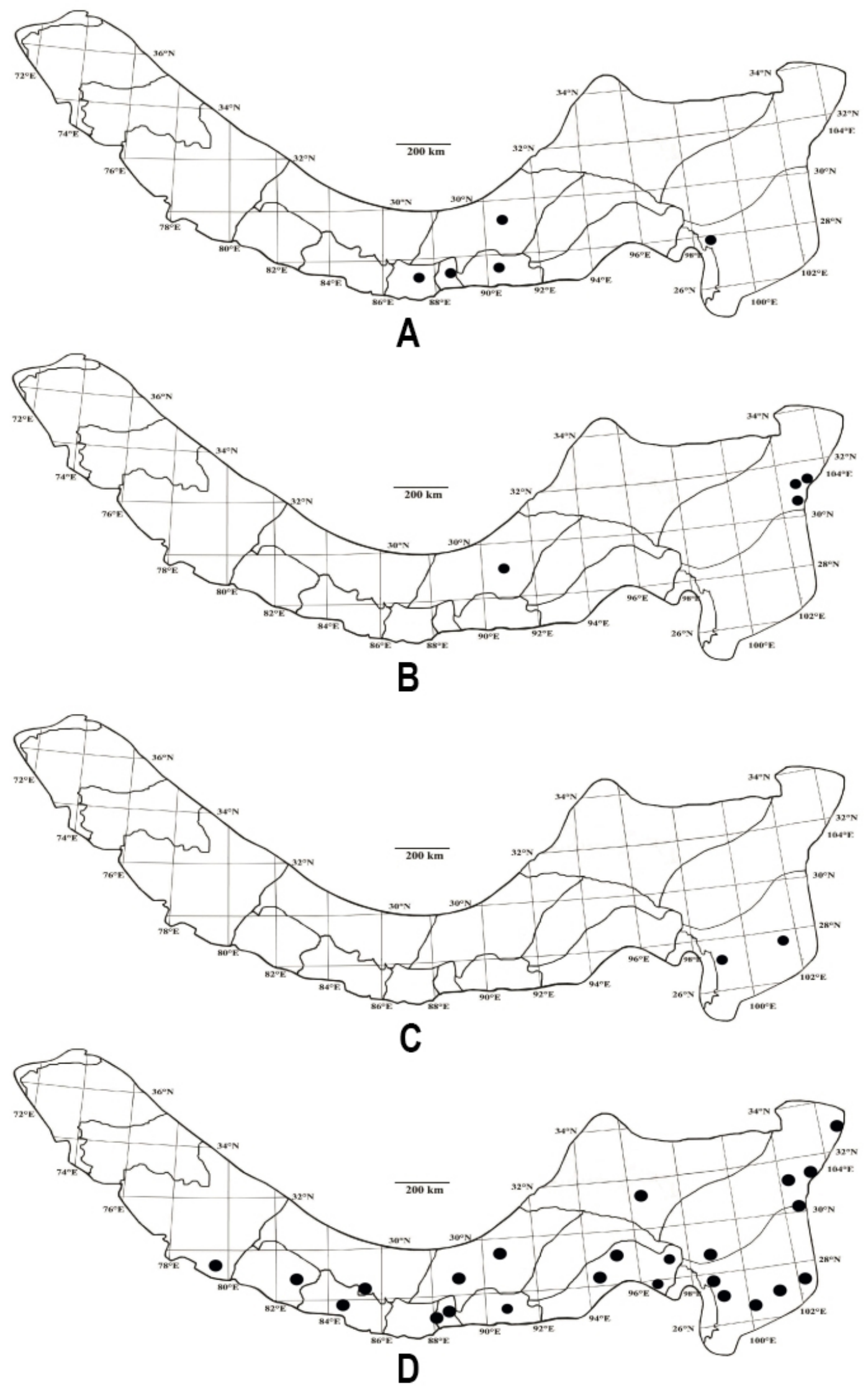

Fig. 13: Distribution of the Hymenophyllum in Pan Himalaya regions: a - Hymenophyllum levingei (C. B. Clarke) Copel.; b - H. corrugatum (Christ) Copel.; c - H. longissimum (Ching \& P. S. Chiu) K. Iwats.; d - H. polyanthos (Sw.) Sw. 
to acuminate, glabrous; pinna 5-10 pairs, basal ones oblong-subdeltoid, up to $3 \times 2 \mathrm{~cm}$, base broadly cuneate to rounded, shortly stalked, apex moderately acute to rounded; upper ones gradually smaller upward, oblong in outline; ultimate segments up to 3-4 $\times 0.8-1 \mathrm{~mm}$, oblong, decurrent, axis distinct, wavy or crisped wings, ca. $0.8 \mathrm{~mm}$ in width, margin entire but undulate or crisped, apex rounded to obtuse. Lamina cell polyhedral, nearly isodiametric, irregular in shape; cell wall slightly thick and straight; marginal cell irregular in shape, marginal cell wall thin and straight. Vein free, alternate, raised on the surface. Sori on the apical portion of the lamina, involucres ovate, bivalvate, 1.4-1.6 $\times$ $1.3-1.8 \mathrm{~mm}$, deeply cleft to base, brown, lips round or subdeltoid, slightly serrate or sometimes nearly entire at margin, receptacle included, clavate to filiform (Fig. 11, 14B).

Distribution in Pan-Himalaya: India (Almora: Pindari, Khati), China (Xizang, Yunnan).

General distribution: China (S. Taiwan, Xizang, Yunnan), East and West Himalaya, throughout India, Indonesia, Myanmar, Sri Lanka,
Malay Peninsula, Philippines, Thailand, Vietnam, Australia (Queensland), Mauritius, Bourbon, Mauritius, Pacific islands (Micronesia, Polynesia).

Habitat: Throughout the mountainous regions growing on moist shaded rocks in forest at 333$3300 \mathrm{~m}$ altitude.

Specimens examined: CHINA, XIZANG, 333 m, G. Forrest 26545 (Hymenophyllum australe); G. Forrest s. n. (Mecodium crispatum); Zayu: Cibagou, $3300 \mathrm{~m}, X$. C. Zhang 5015 (M. crispatum); Medog: 2200 m, 1750 m, Ecological Team Plateau Group 14050 (M. crispatum); W. L. Chen 10709 (M. crispatum).

\section{Disscussion and conclusion}

The Pan-Himalaya consists of the highest mountains and plateau of the world and is phytogeographically unique. From south to north, the mountains may be grouped into four parallel and longitudinal belts, i.e. The Shivaliks (The Outer Himalayas), The Himachal (The Lesser Himalayas), The Himadri (The Greater Himalayas), and the Trans Himalayas (Tibetan Himalayas). From west

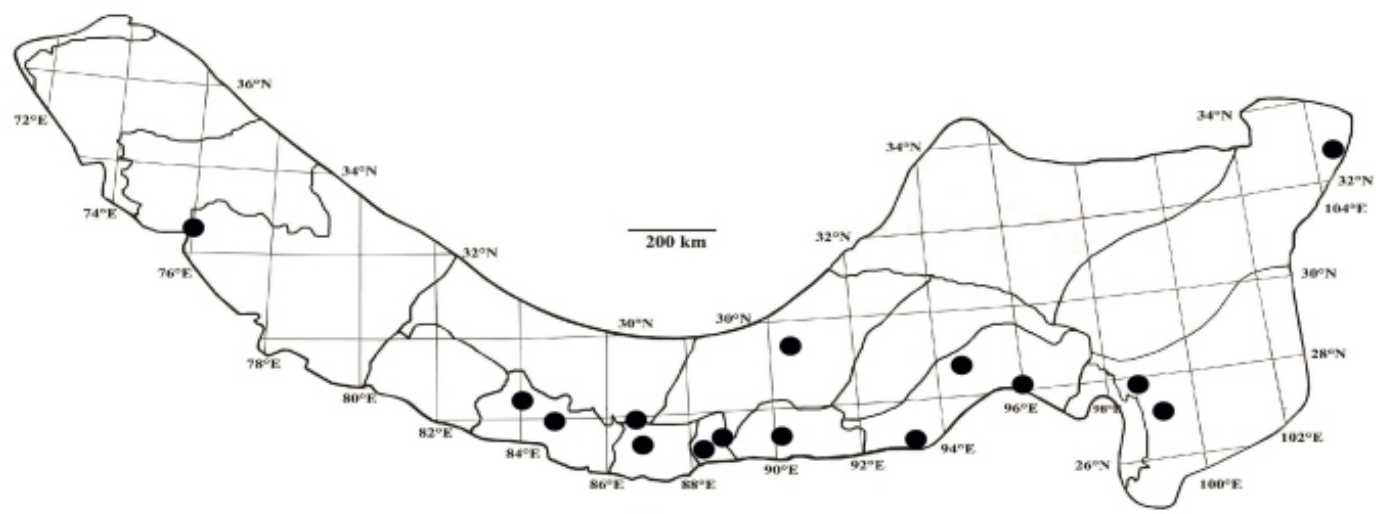

A

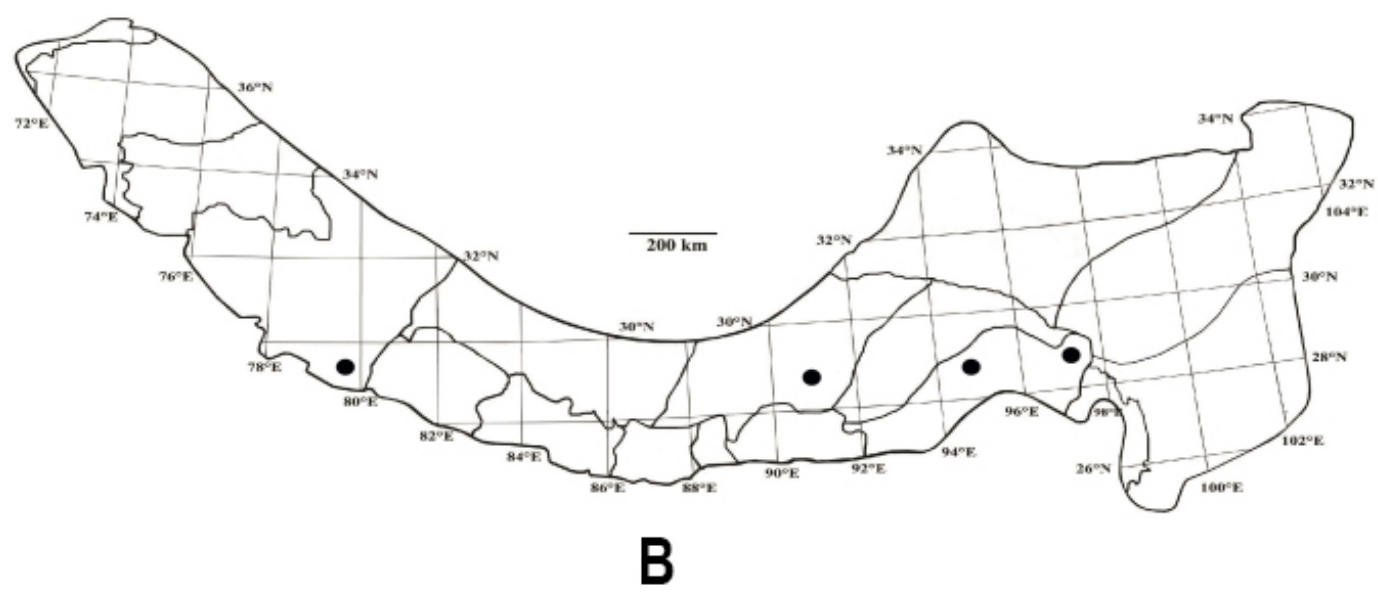

Fig. 14: Distribution of the Hymenophyllum in Pan Himalaya regions: a - Hymenophyllum badium Hook. \& Grev.; $\mathrm{b}-$ H. javanicum Spreng. 
to east, the Himalayas may broadly divide into three mountainous regions, the Western Himalayas, the Central Himalayas, and the Eastern Himalayas. It is home to several important biodiversity hotspots. Many floristic accounts on Pteridophytes have been carried out in Himalayan regions, such as Chandra (2000); Chandra et al. (2008); Clarke (1880); FraserJenkins (1992, 1997, 2008, 2010, 2012); FraserJenkins, Benniamin (2010); Ghosh et al. (2004); Itô et al. (1971); Itô et al. (1966); Iwatsuki (1975, 1985, 1988); Khullar, Fraser-Jenkins (1994, 2000); Mehra, Bir (1964); Pande, Pande (2002); Thapa (2001, 2002).

With regard to the status of Hymenophyllum, it has been very little known in the Himalayan regions. Therefore, the present investigation focused on the Hymenophyllum distributed in Pan-Himalaya. According to the classification system of Ebihera et al. (2006), in the studied area, five species: Hymenophyllum barbatum, $H$. denticulatum, $H$. exsertum, $H$. levingei, $H$. simosianum belong to subgenus Hymenophyllum; 3 species: $H$. corrugatum, $H$. longissimum, $H$. polyanthos belong to subgenus Mecodium and 2 species: $H$. badium and $H$. javanicum belong to subgenus Globosa. H. corrugatum and H. longissimum are endemic to China, while $H$. barbatum is endangered and $H$. levingei is globally threatened species which are needed to be conserved and maintained for sustainability.

\section{Acknowledgements}

We wish to express sincere thanks to the curators and supporting staffs of PE herbarium for their kind permission to study the specimen and use facilities. We would like to express the gratitude to Mr. Christopher Fraser-Jenkins and Nawal Shrestha for providing relevant literature and information and also extended to Dr. Ebihara for providing pictures of specimens and valuable advices. Special thanks to Professor Zenith Oo and Mr. Christopher Fraser-Jenkins for their valuable suggestions. The work was supported by the CASTWAS postdoctoral Fellowship program, 2012 (FR number: 3240267233).

\section{REFERENCES}

Chandra S. 2000. The ferns of India (Enumeration, Synonyms \& Distribution). International Book Distributors, Dehra Dun, 459 pp.

Chandra S., Fraser-Jenkins C. R., Kumari A., Srivastava A. 2008. A summary of the status of threatened pteridophytes of India. Taiwania 53(2): 170-209.

Clarke C. B. 1880. A review of the ferns of northern India. Trans. Linn. Soc. (Lond.), ser. 2, Bot. 1: $425-619$.

Dickason F. G. 1947. The Ferns of Burma. Ohio J. Sci. 46, 3: 109-141.

Ebihara A., Dubussion J-Y., Iwatsuki K., Hennequin S., Ito M. 2006. A taxonomic revision of Hymenophyllaceae. Blumea 51: 221-280.

Fraser-Jenkins $\boldsymbol{C} . \boldsymbol{R}$. 1992. The ferns and allies of the far west Himalaya. Pakistan Systematics 5, 1-2: 85-120.

Fraser-Jenkins C. R. 1997. New species syndrome in Indian pteridology and the ferns of Nepal: $i$-v, with separate errata. International Book Distributors, Dehra Dun, India, 403 pp.

Fraser-Jenkins $\boldsymbol{C}$. $\boldsymbol{R}$. 2008. Endemics and pseudo-endemics in relation to the distribution patterns of Indian Pteridophytes. Taiwania 53, 3: 264-292.

Fraser-Jenkins C. R. 2010. Nepal's little known pteridophytes, the hidden work of David Don, and the geography and distribution of Indo-Himalayan ferns. With State list. URL: https://sites.google.com/site/efloraofindia/files (Accessed 15 May 2017).

Fraser-Jenkins C. R. 2012. Rare and Threatened Pteridophytes of Asia 2. Endangered Species of India - the Higher IUCN Categories. Bull. Natl. Mus. Nat. Sci., Ser. B, 38, 4: 153-181.

Fraser-Jenkins $\boldsymbol{C}$. R., Benniamin, A. 2010. Fifty rarities and additions to the pteridophytic flora of Arunachal Pradesh state on the north-east frontier of India. Panjab Univ. Res. J. Sci. 59: 1-38.

Fraser-Jenkins C. R., Kandel D. R., Pariyar S. 2015. Ferns and Fern-allies of Nepal-1. National Herbarium and Plant Laboratories, Department of Plant Resources, Ministry of Forests and Soil Conservation, Kathmandu, Nepal, 508 pp.

Fraser-Jenkins C. R., Matsumoto S., Wangdi T. 2009. Pteridophytes of Bhutan - A list of families, genera and species. Ed. C. R. Fraser-Jenkins. National Biodiversity Centre, Ministry of Agriculture, Serbithang, Thimphu, Bhutan, i-X, $125 \mathrm{pp}$.

Ghosh S. R., Ghosh B., Biswas A., Ghosh R. K. 2004. The Pteridophytic Flora of Eastern India 1. Flora of India. Series 4. Botanical survey of India, Kolkata, $591 \mathrm{pp}$.

Itô H., Iwatsuki K., Tagawa M. 1971. Pteridophyta. In: The flora of eastern Himalaya. Ed. H. Hara. Second report. Univ. Tokyo Bull. 2: 197-221. 
Itô H., Tagawa M., Nishida M., Iwatsuki K. 1966. Pteridophyta. In: The flora of eastern Himalaya. Ed. H. Hara. University of Tokyo, Tokyo, 453-500 pp.

Iwatsuki K. 1975. Pteridophyta. In: Flora of Eastern Himalaya. Ed. H. Ohashi. The University Museum, the University of Tokyo, Tokyo, 8: 166-205.

Iwatsuki K. 1985. The Hymenophyllaceae of Asia, excluding Malesia. J. Fac. Sci. Univ. Tokyo, Sect. 3, Bot. 13: 501-551.

Iwatsuki K. 1988. An enumeration of the pteridophytes of Nepal. In: The Himalayan Plants. Eds. H. Ohba, S. B. Malla. University of Tokyo Press, Tokyo, 1: 231-339.

Iwatsuki K. 1990. Hymenophyllaceae. In: The families and genera of vascular plants. The families and genera of vascular plants. Pteridophytes and Gymnosperms. Ed. K. Kubitzki. Springer Verlag, Berlin, 1: 157-163 pp.

Khullar S. P., Fraser-Jenkins C. R. 1994. An illustrated Fern Flora of West Himalaya 1. International Book Distributors, Dehra Dun, India, 506 pp.

Khyllar S. P., Fraser-Jenkins C. R. 2000. An illustrated Fern Flora of the West Himalaya 2. International Book Distributors, Dehra Dun, India, $544 \mathrm{pp}$.

Liu J. X., Zhang Q. Y., Ebihara A., Iwatsuki K. 2013. Hymenophyllacae Mart. In: Flora of China. Eds. Z. Y. Wu, P. H. Raven, D. Y. Hong. Beijing: Science Press; St. Louis: Missouri Botanical Garden Press, 2-3 (Pteridophytes): 93-109.

Mehra P. N., Bir S. S. 1964. Pteridophytic flora of Darjeeling and Sikkim Himalayas. Res. Bull. Panjab. Univ., n. s., 15, 1-2: 69-181.

Pande P. C., Pande H. C. 2002. Pteridology in Western Himalaya (Kumaun). Bishen Singh Mahendra Pal Singh, Dehra Dun, 215 pp.

Singh S., Panigrahi G. 2005. Ferns and Fern-allies of [Triap District] Arunachal Pradesh 1. Bishen Singh Mahendra Pal Singh, Dehra Dun, 426 pp.

Thapa N. 2001. Ferns and Fern Allies of the Milke-Jaljale Area, Nepal, in the Eastern Himalayas. Newsletter Himalayan Bot. 27: 8-17.

Thapa N. 2002. Pteridophytes of Nepal. Bulletin of the Department of Plant Resources 19: 1-175. 